\title{
Development of Heterocycle-Substituted and Fused Azulenes in the Last Decade (2010-2020)
}

\author{
Taku Shoji ${ }^{1, *(\mathbb{D})}$, Tetsuo Okujima ${ }^{2, *(D)}$ and Shunji Ito ${ }^{3, *(\mathbb{C}}$ \\ 1 Department of Material Science, Graduate School of Science and Technology, Shinshu University, \\ Matsumoto 390-8621, Japan \\ 2 Department of Chemistry and Biology, Graduate School of Science and Engineering, Ehime University, \\ Matsuyama 790-8577, Japan \\ 3 Graduate School of Science and Technology, Hirosaki University, Hirosaki 036-8561, Japan \\ * Correspondence: tshoji@shinshu-u.ac.jp (T.S.); okujima.tetsuo.mu@ehime-u.ac.jp (T.O.); \\ itsnj@hirosaki-u.ac.jp (S.I.); Tel.: +81-263-37-2476 (T.S.); +81-89-927-9615 (T.O.); +81-172-39-3568 (S.I.)
}

Received: 16 September 2020; Accepted: 22 September 2020; Published: 25 September 2020

\begin{abstract}
Azulene derivatives with heterocyclic moieties in the molecule have been synthesized for applications in materials science by taking advantage of their unique properties. These derivatives have been prepared by various methods, involving electrophilic substitution, condensation, cyclization, and transition metal-catalyzed cross-coupling reactions. Herein, we present the development of the synthetic methods, reactivities, and physical properties for the heterocycle-substituted and heterocycle-fused azulenes reported in the last decade.
\end{abstract}

Keywords: azulene; heterocycles; synthetic method; reactivity

\section{Introduction}

Azulene (1) is one of the $10 \pi$-electron non-benzenoid aromatic hydrocarbons having a fused structure of 5- and 7-membered rings. Azulene (1) is one of the structural isomers of naphthalene, however, the color of these isomers differ greatly from each other. Despite the fact that naphthalene is a colorless compound, azulene (1) shows a beautiful blue color. The name "azulene" derives from the Arabic word "azur" and the Spanish word "azul" which both mean "blue". Azulene (1) has the contribution of the cyclopentadienide and tropylium substructures as shown in Scheme 1. Hence, despite being a hydrocarbon, azulene (1) shows a relatively large dipole moment (1.08 debye). Furthermore, electrophilic substitution reaction of azulene (1) proceeds at 1-, 3-, 5-, and 7-positions, while nucleophilic addition reaction takes place at 4-, 6-, and 8-positions. Some azulene derivatives have pharmacological activity, and azulene sulfonic acid derivatives are especially used as anti-inflammatory drugs [1-3]. In recent years, azulene derivatives have also been reported to exhibit anti-tumor activity [4-7].

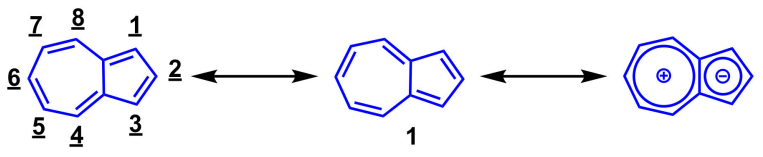

Scheme 1. Resonance structure and numbering scheme of azulene (1).

Due to their unique optical and electrochemical properties, heterocycle-substituted and heterocycle-fused azulene derivatives are expected to be applied to organic materials such as organic light-emitting diodes (OLEDs), organic field effect transistors (OFETs), solar cells, and biosensors. 
Therefore, many researchers have studied the synthesis, reactivity, and properties of these derivatives, as discussed below. Several review articles on the classical heterocycle-substituted and heterocycle-fused azulene derivatives have been published so far [8-17]. However, there is no systematic review of the progress in the synthesis and reactivity of these derivatives within the last decade. Herein, we describe the development of heterocycle-substituted and heterocycle-fused azulene derivatives in the last decade.

\section{Synthesis and Reactivity of Azulene Derivatives with 6-Membered Ring Heterocycles}

\subsection{Azulene Derivatives with N-Containing 6-Membered Heterocycles}

Nitrogen-containing (N-containing) 6-membered heterocycles, such as pyridine, are an important substructure found in pharmaceuticals and natural products. Therefore, the synthesis and reactivity of these derivatives with $\mathrm{N}$-containing 6-membered heterocycles have been reported in relatively large numbers.

In 2010, Wu et al. reported the two- or three-step synthesis of azulenopyridazines $6 \mathrm{a}$ and $6 \mathrm{~b}$ from 4-hydrazinylazulene 3, which were prepared by the $S_{N}$ Ar reaction of 4-ethoxyazulene 2 with hydrazine $\left(\mathrm{N}_{2} \mathrm{H}_{4}\right)$ [18]. The reaction of 3 with ketones in $\mathrm{EtOH}$ gives the corresponding hydrazones $4 \mathrm{a}$ and $4 \mathrm{~b}$ in excellent yields. When the hydrazones $4 \mathrm{a}$ and $4 \mathrm{~b}$ are treated with $p$-toluenesulfonic acid ( $p$-TSA), dihydropyridazines $5 \mathrm{a}$ and $5 \mathrm{~b}$ can be obtained in $87 \%$ and $94 \%$ yields, respectively. Both hydrazones $4 \mathrm{a}, 4 \mathrm{~b}$ and dihydropyridazines $5 \mathrm{a}, 5 \mathrm{~b}$ afford the corresponding azulenopyridazines $6 \mathrm{a}$ and $6 \mathrm{~b}$ by the treatment with $\mathrm{KOH}$ in $\mathrm{MeOH}$ in excellent yields (Scheme 2).

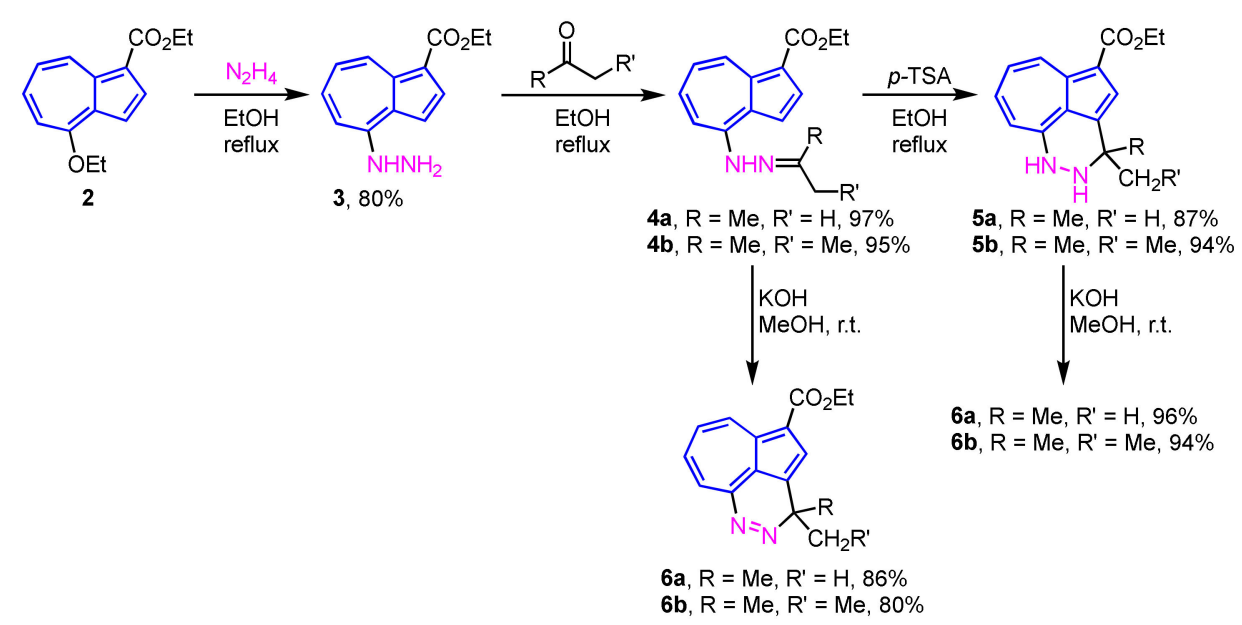

Scheme 2. Syntheses of azulenopyridazines $6 \mathbf{a}$ and $\mathbf{6 b}$ from 4-hydrazinylazulene 3.

A facile synthesis of 2-substituted 2,3-dihydro-4(1H)-azuleno[2,1-d]pyrimidinones 8 was demonstrated by Wang and co-workers (Scheme 3) [19]. In their procedure, Brønsted acid-catalyzed reaction of 2-amino-3-carbamoylazulene 7 with ketones or aldehydes in 2,2,2-trifluoroethanol gives the azulene-fused dihydropyrimidinones 8 in moderate to excellent yields.

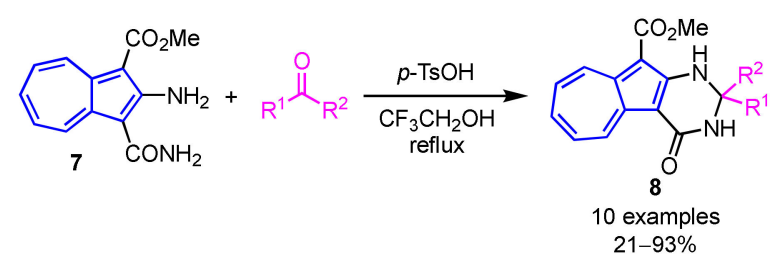

Scheme 3. Synthesis of 2,3-dihydro-4(1H)-azuleno[2,1- $d$ ]pyrimidinones 8 by the condensation of 2-amino-3-carbamoylazulene 7 with carbonyl compounds. 
Yli-Kauhaluoma et al. reported the synthesis of azulene-fused $\delta$-lactams 11, 12a, and $\mathbf{1 2 b}$ by the sequential nucleophilic and intramolecular cyclization reactions of 4-aminoazulene (10), which was prepared from guaiazulene (9) in five steps, including Curtius-Schmidt rearrangement, with the corresponding 1,2-diketones (Scheme 4) [20].

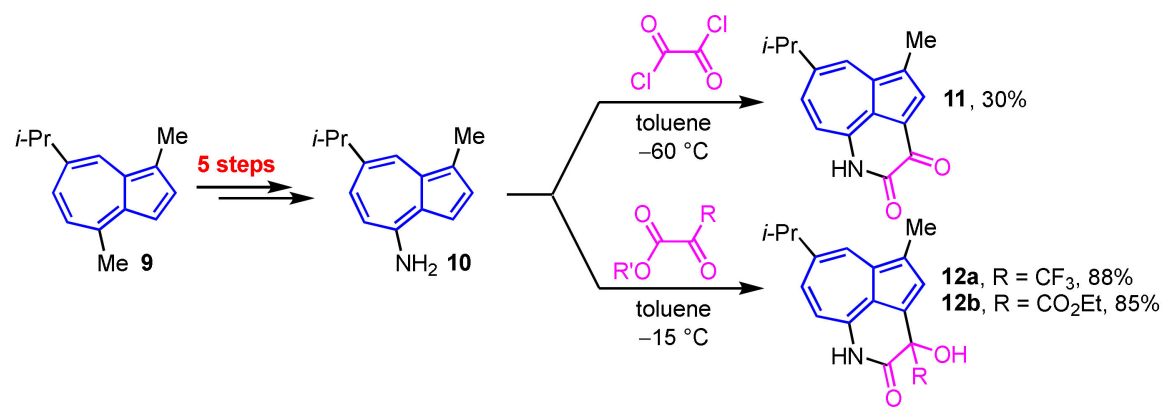

Scheme 4. Synthesis of azulene-fused $\delta$-lactams 11, 12a and 12b from 4-aminoguaiazulene (10).

Synthesis of 1-(2-pyridyl)azulenes 14 and 15 bearing a thiol and a methylthio group at the 2-position was reported by Wakabayashi and his colleagues (Scheme 5) [21]. They investigated the metal ion sensitivity of these compounds and found that $\mathbf{1 4}$ and $\mathbf{1 5}$ show color change with addition of $\mathrm{Hg}^{2+}$ ion.

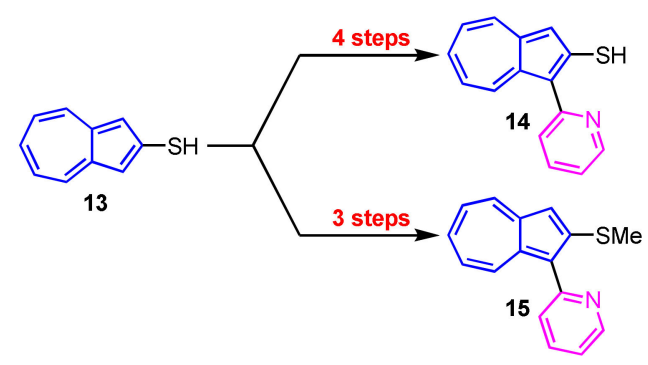

Scheme 5. Synthesis of 1-(2-pyridyl)azulenes 14 and 15 with a sulfur function at the 2-position.

In 2013, Wang et al. developed a preparation method of $11 H(2 H)-4$ oxopyrazolo[ $\left[3^{\prime}, 4^{\prime}: 6,5\right]$ pyrido[3,2-a]azulene derivatives 17 by the domino reaction of $\mathbf{1 6}$ with hydrazines in moderate to good yields (Scheme 6) [22]. A simple procedure for azuleno[2,1-b]pyridazines 19 was also reported by the same group. In this reaction, azuleno[2,1-b]pyridazines 19 are obtained by the condensation between 1-cyanoacetyl-2-methoxyazulene $\mathbf{1 8}$ and aryldiazonium salts in pyridine in good yields (Scheme 7) [23].
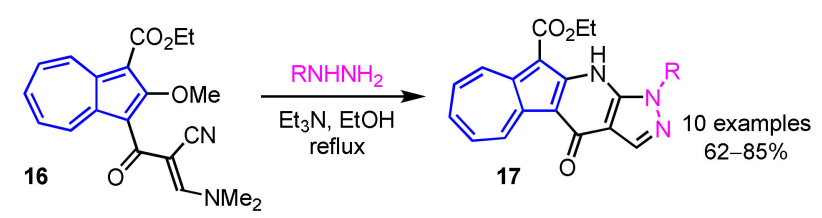

Scheme 6. Synthesis of $11 H(2 H)$-4-oxopyrazolo $\left[3^{\prime}, 4^{\prime}: 6,5\right]$ pyrido[3,2-a]azulenes 17 by the domino reaction.

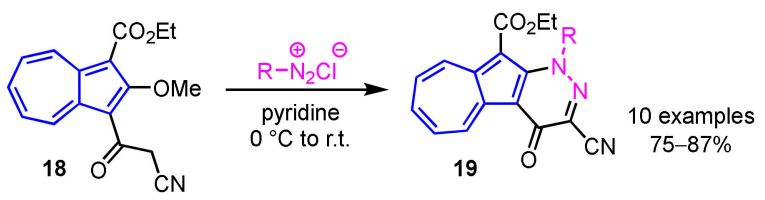

Scheme 7. Synthesis of azuleno[2,1-b]pyridazines 19 from 1-cyanoacetyl-2-methoxyazulene 18. 
The Reissert-Henze-type reaction is applicable to the synthesis of 1-(2-pyridyl)azulene (21) and its derivatives $22 \mathrm{a}$ and $\mathbf{2 2 b}$. The reaction of $\mathbf{1}, \mathbf{2 0 a}$ and $\mathbf{2 0 b}$ with pyridine $N$-oxide in the presence of trifluoromethanesulfonic anhydride $\left(\mathrm{Tf}_{2} \mathrm{O}\right)$ yields $21,22 \mathbf{a}$ and $22 \mathbf{b}$ in moderate to good yields (Scheme 8) [24]. This procedure is also applicable to the substituted pyridine $\mathrm{N}$-oxides and quinoline $\mathrm{N}$-oxide, which react with azulenes to produce the corresponding 1-(2-pyridyl- and 2-quinolyl)azulenes.

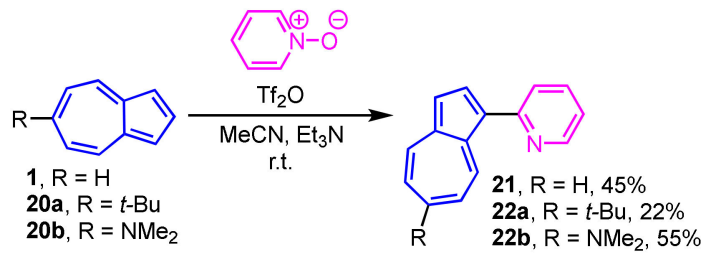

Scheme 8. Synthesis of 1-(2-pyridyl)azulenes 21, 21a, and 22b.

The synthesis of 2-heteroarylazulenes via electrophilic substitution reaction was first described in 2012. The reaction of 6-dimethylamino-1,3-bis(methylthio)azulene (23) with pyridine in the presence of $\mathrm{Tf}_{2} \mathrm{O}$, followed by treatment with $\mathrm{KOH}$, gives 2-(4-pyridyl)azulene 24 (Scheme 9) [25]. In a similar reaction, it is possible to employ quinoline, acridine, and 1,10-phenanthroline to furnish the corresponding 2-heteroarylazulene derivatives. This method is the first example of the synthesis of 2-heteroarylazulenes via an electrophilic substitution reaction.

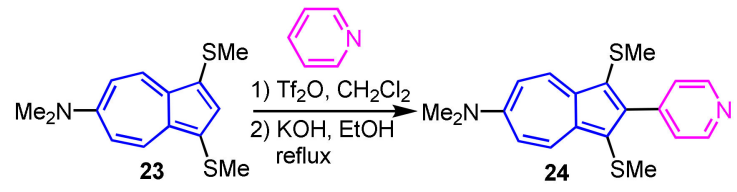

Scheme 9. Synthesis of 2-(4-pyridyl)azulene derivative 24 via electrophilic substitution.

The palladium-catalyzed cross-coupling reaction of 2-iodoazulene (25) and 6-bromoazulene (26) with lithium pyridyl and quinolyl magnesium ate-complexes affords the corresponding 2- and 6-heteroarylazulene derivatives 27 and 28 in good to excellent yields (Scheme 10) [26]. The reaction of 27 and 28 with pyridine in the presence of $\mathrm{Tf}_{2} \mathrm{O}$ and subsequent aromatization with $\mathrm{KOH}$ gives the corresponding tris(heteroaryl)azulenes 29 and 30.

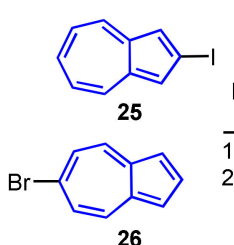

26

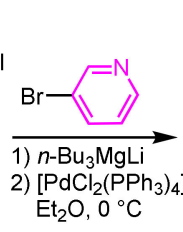

$\mathrm{Et}_{2} \mathrm{O}, 0^{\circ} \mathrm{C}$

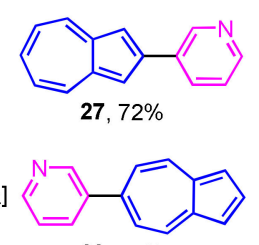

28, $70 \%$
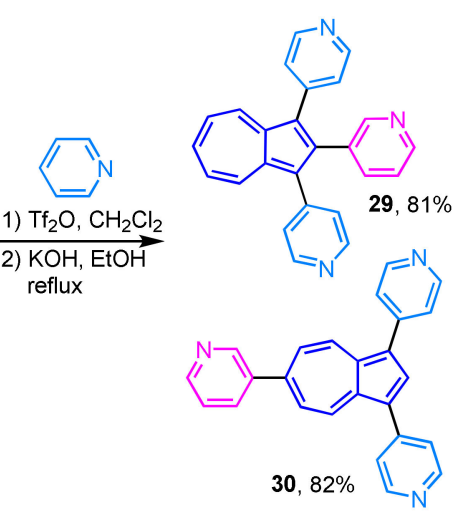

Scheme 10. Synthesis and pyridinylation of 2- and 6-(3-pyridyl)azulenes 27 and 28.

Preparation of 2-heteroarylazulenes by the Negishi cross-coupling reaction was achieved in two ways by Bredihhin et al. The first is the reaction of 2-bromoazulene (31) with a zinc reagent of the heterocycles, where the cross-coupling reaction of 31 with 4-pyridyl zinc reagent at room temperature yields 2-(4-pyridyl)azulene (32) in 76\% yield (Scheme 11) [27]. In another way, 2-azulenyl zinc reagent 34 , which is prepared from 2-iodoazulene derivative 33 , reacts with heteroaryl bromides 
at room temperature to give 2-(pyridyl- and primidinyl)azulene derivatives 35 and 36 in good yields. In this case, the 2-azulenyl zinc reagent 34 can be prepared by the direct metalation of 1,3-dichloro-2-iodoazulene (33) precursor with $i$-PrMgCl- $\mathrm{LiCl}$, then transmetalation with zinc chloride (Scheme 12) [28].

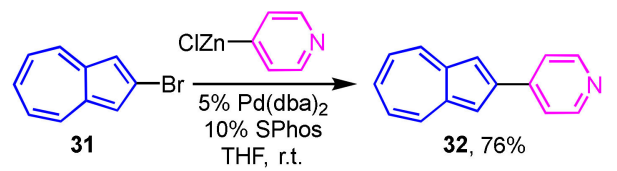

Scheme 11. Synthesis of 2-(4-pyridyl)azulene (32) using a heteroaryl zinc reagent.

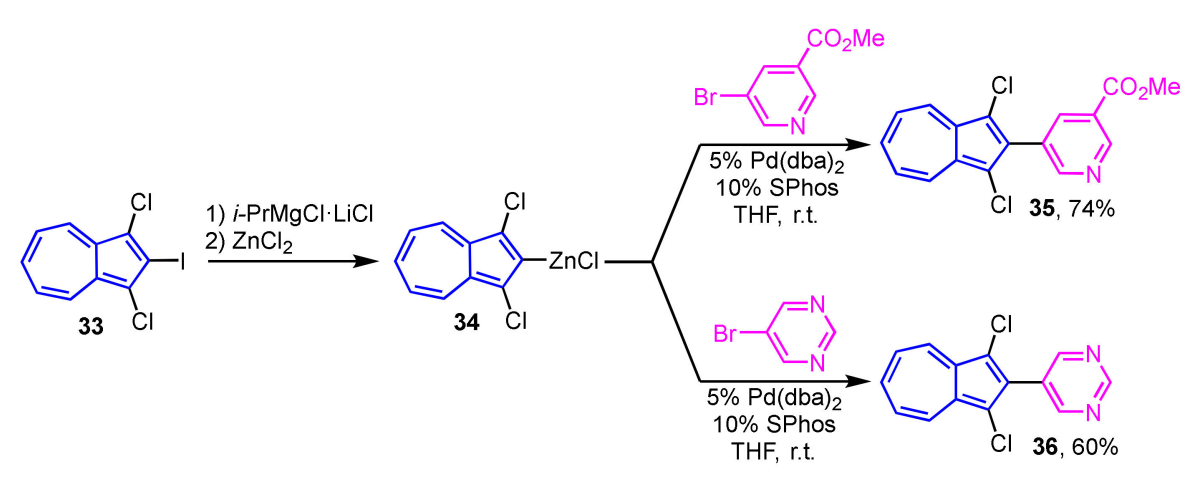

Scheme 12. Synthesis of 2-(pyridyl- and pyrimidiyl)azulenes 35 and 36 by Negishi cross-coupling reaction using 2-azulenyl zinc reagent 34 .

1-Haloazulenes, such as 1-bromo- and 1-iodoazulenes, are known to be unstable compounds. Lewis and co-workers demonstrated the preparation of 1-heteroarylazulenes by the cross-coupling reaction of aryl boronic acids with 1-azulenylsulfonium salt 37, instead of the 1-haloazulenes [29]. In this procedure, the reaction of the 1-azulenylsulfonium salt 37 with the boronic acids or acid esters of the heterocycles in the presence of a palladium/XPhos catalyst affords the corresponding 1-heteroarylazulenes 38 and 39 (Scheme 13). This method is also applicable to the synthesis of 1-(2-thienyl)azulenes. Details of the synthesis of these derivatives are described later.

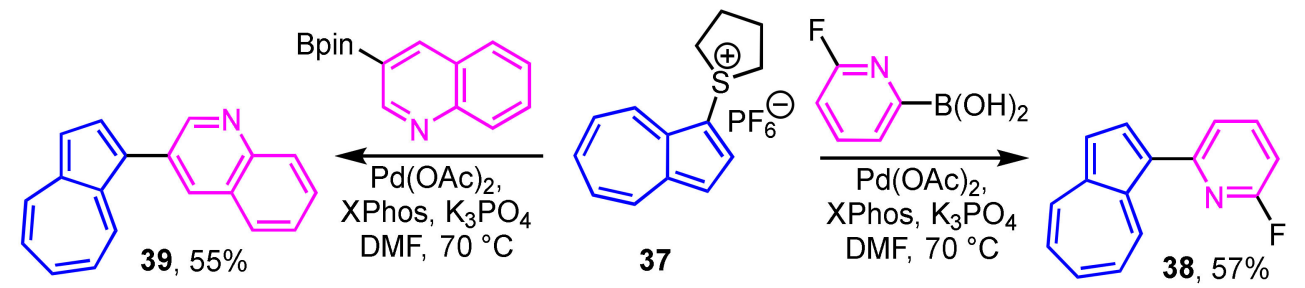

Scheme 13. Synthesis of 1-(2-pyridyl)- and 1-(3-quinolyl)azulenes 38 and 39 from 1-azulenylsulfonium salt 37.

In 2016, Nica et al. reported the multistep synthesis of $2,2^{\prime}: 6^{\prime}, 2^{\prime \prime}$-terpyridine-substituted azulene derivatives under the Kröhnke-type reaction conditions (Scheme 14) [30]. Condensation of 40 with 2-acetylpyridine under grinding conditions leads to the corresponding azulene-substituted chalcone 41 in $72 \%$ yield. Compound 41 is subjected to further reaction with 2-acetylpyridine under the same conditions, then the microwave (MW) irradiation in the presence of ammonium acetate to form 4-(1-azulenyl)terpyridine $\mathbf{4 2}$ in $42 \%$ yield. 


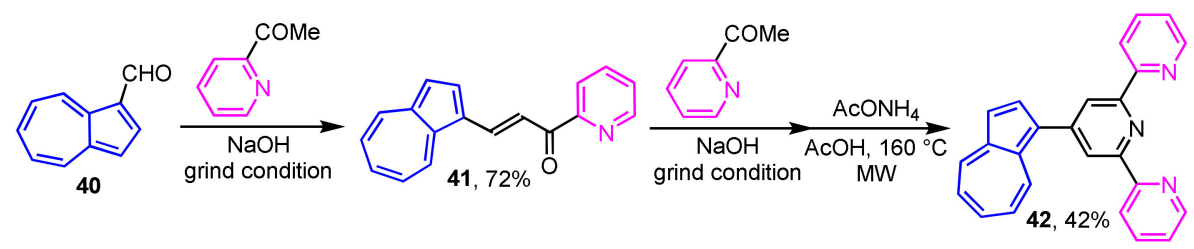

Scheme 14. Preparation of $2,2^{\prime}: 6^{\prime}, 2^{\prime \prime}$-terpyridine-substituted azulene 42.

The polycyclic aromatic hydrocarbons (PAHs) in which a part of the $\mathrm{C}=\mathrm{C}$ moiety is replaced with a B-N unit has attracted considerable attention in the field of materials science. Recently, Gao et al. reported the preparation of two azulene-fused BN-heterocycles 45 and 47 via aromatic borylation of 44 and 46 (Scheme 15) [31]. Compounds 45 and 47 exhibit unique absorption and fluorescence properties unlike those of previously reported BN-embedded PAHs. Furthermore, 45 and 47 show high sensitivity toward fluoride ion, and a remarkable color change is observed by the addition of the ion.

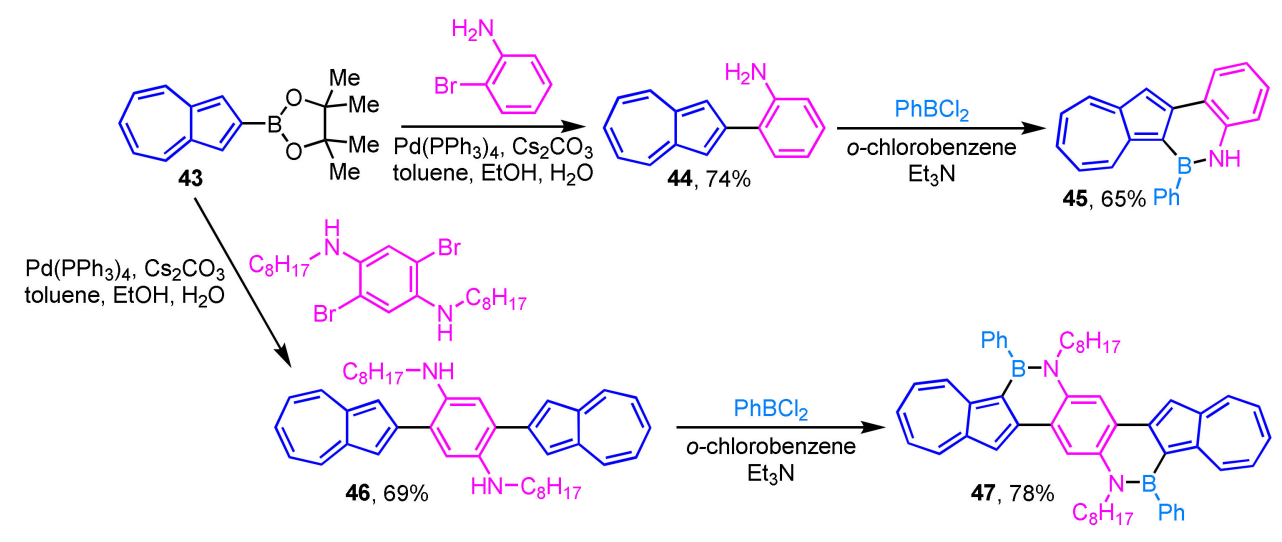

Scheme 15. Synthesis of azulene-fused BN-heterocycles 45 and 47 via aromatic borylation.

\subsection{Azulene Derivatives with O-Containing 6-Membered Heterocycles}

Several examples of azulene derivatives, which are substituted or fused by oxygen-containing (O-containing) 6-membered heterocycles, have been reported. The synthesis of these derivatives is mainly established by the intermolecular or intramolecular cyclization reactions.

In 2012, Wang et al. reported the synthesis of 2-amino-3-cyano-4-aryl-10-ethoxycarbonylazuleno [2,1-b]pyrans 49 from 2-hydroxyazulene derivative 48 (Scheme 16) [32]. The three-component cascade reaction of 48, arylaldehydes and malononitrile in the presence of diazabicyclo[2.2.2]octane (DABCO) as a base produces the corresponding products 49 in excellent yields.

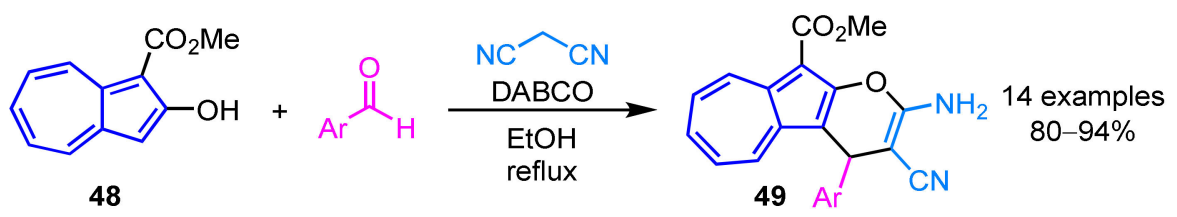

Scheme 16. Synthesis of 2-amino-3-cyano-4-aryl-10-ethoxycarbonylazuleno[2,1-b]pyrans 49 from 2-hydroxyazulene derivative 48 .

Sato et al. demonstrated the preparation of tricyclic compound 52 connected with 3-aminoguaiazulene by the multicomponent reaction of 3-isocyanoguaiazulene 50, dimethyl acetylenedicarboxylate (DMAD), and 4-hydroxycoumarin (51) (Scheme 17) [33]. This reaction also allows synthesis of the corresponding furan or hydropyridine derivatives by using an aldehyde or aniline derivatives instead of 4-hydroxycoumarin. 


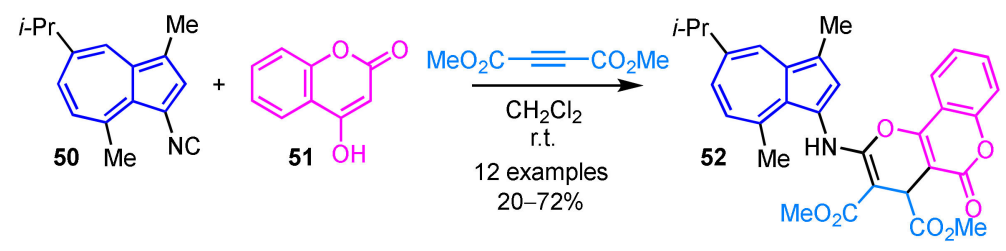

Scheme 17. Synthesis of tricyclic compound 52 connected with 3-aminoguaiazulene by the multicomponent reaction.

The $\mathrm{AlCl}_{3}$-mediated cyclization reaction of 2-hydroxyazulenes 53a and $53 \mathbf{b}$ with activated methylene compounds gives pyrone-fused azulene derivatives (azulenopyranones 54a-54c) in low to moderate yields (Scheme 18) [34]. The reaction of 54a with $N$-bromosuccinimide (NBS) results in conversion into the bromides $\mathbf{5 5}$ and $\mathbf{5 6}$. When one equivalent of NBS is used, $\mathbf{5 5}$ is obtained in $42 \%$ yield along with 56 in $31 \%$ yield. While, the dibromo derivative 56 is selectively generated in excellent yield (91\%), when two equivalents of NBS is employed. Compounds 55 and 56 can be further functionalized by the palladium-catalyzed cross-coupling reaction.

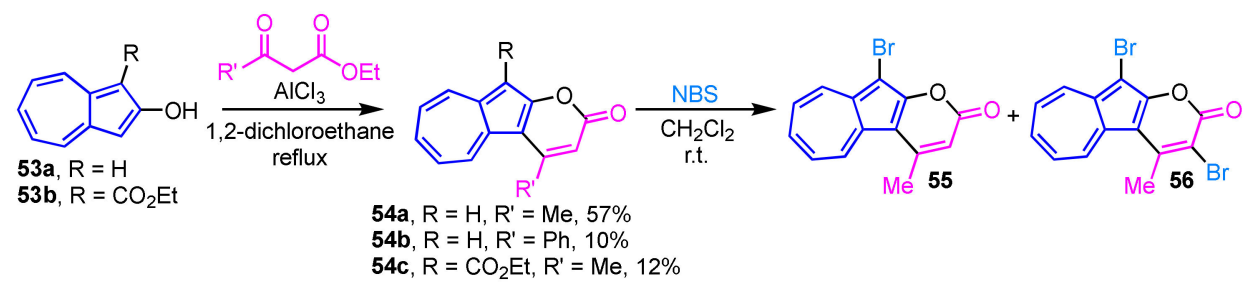

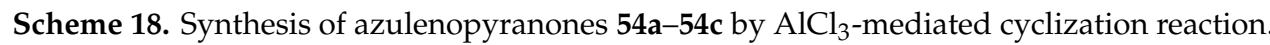

Intramolecular cyclization of alkyne 57 in the presence of trifluoroacetic acid produces isocoumarin derivative 59a in excellent yield (Scheme 19) [35], whereas iodocyclization of alkyne 57 with $\mathrm{N}$-iodosuccinimide (NIS) gives the corresponding 4-iodoisocoumarin $59 \mathrm{~b}$ in moderate yield. Similarly, alkyne $\mathbf{5 8}$ having two azulenyl moieties is treated with trifluoroacetic acid in a mixed solvent of THF and water to give pyrone-fused azulene $\mathbf{6 0}$ in 90\% yield [36].

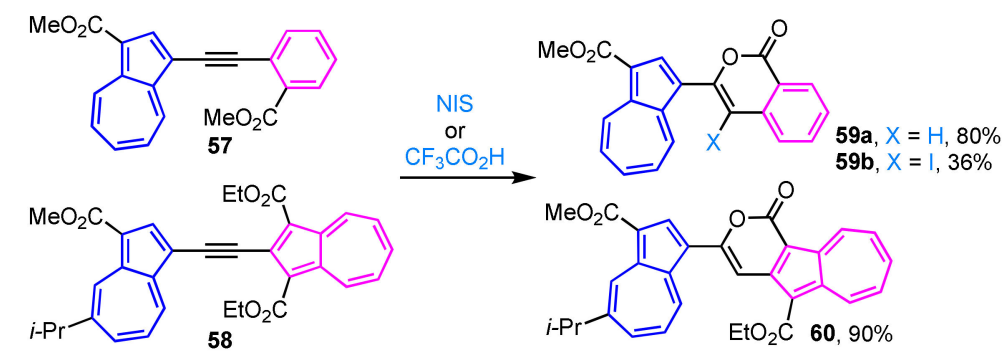

Scheme 19. Synthesis of azulene-substituted isocoumarins 59a, 59b and pyrone-fused azulene 60 by intramolecular cyclization of 1-azulenyl alkynes.

\section{Synthesis and Reactivity of Azulene Derivatives with 4-, 5-, 6-, and 7-Membered Ring Heterocycles}

\subsection{Azulene Derivatives with S-Containing 4-, 5-, 6-, and 7-Membered Heterocycles}

Thiophene, TTF, and the other sulfur-containing heterocycles are expected to be applied in the field of organic electronic materials such as organic semiconductors. For this reason, many efforts have been focused on the incorporation of such heterocycles into azulene derivatives by cross-coupling, cycloaddition, and condensation reactions. 
Preparation of bis(6-azulenylethynyl)thiophene 62, terthiophene 63, and dithienothiophene 64 is examined by the palladium-catalyzed cross-coupling reaction of 6-ethynylazulene 61 with diiodothiophene and the corresponding diiodides under Sonogashira-Hagihara conditions (Scheme 20) [37]. The absorption band of these compounds in their UV/Vis spectra spreads into the near-infrared region due to the decrement of HOMO-LUMO energy gap basis on the expansion of the $\pi$-conjugated system.

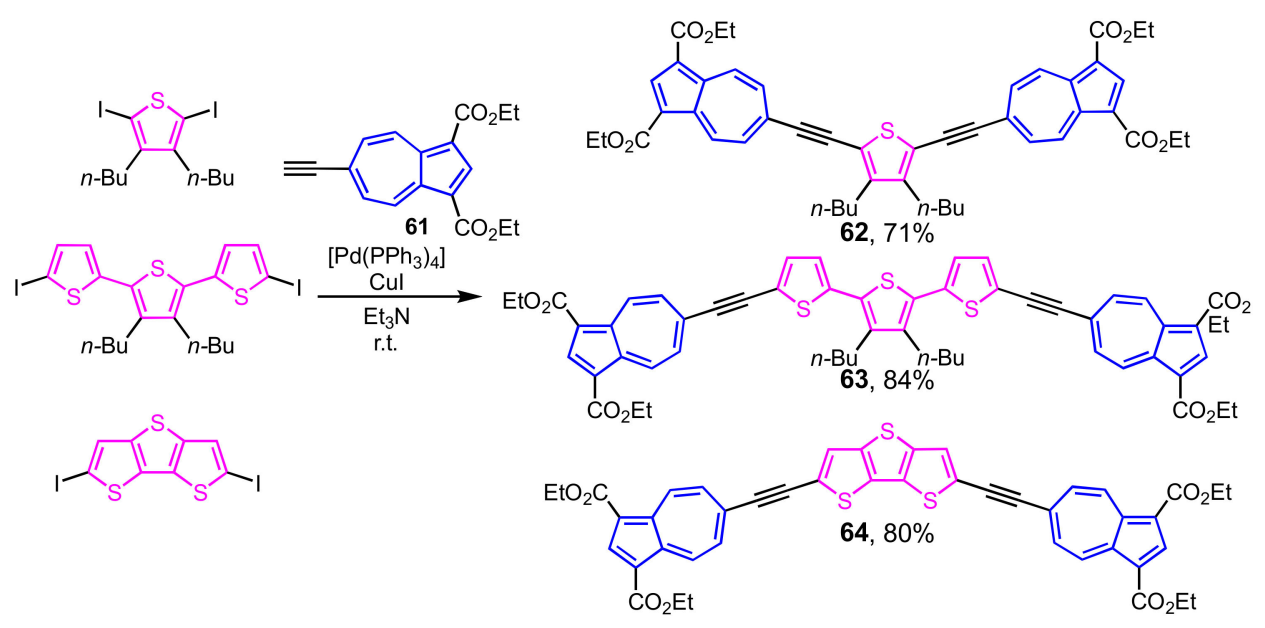

Scheme 20. Synthesis of bis(6-azulenylethynyl)thiophenes 62-64 by Sonogashira-Hagihara cross-coupling reaction.

Synthesis and reactivity of azulenopentathiepin 65 were reported by Sato and his co-workers. Azulenopentathiepin 65 is prepared by the reaction of azulene (1) with elemental sulfur in pyridine under reflux conditions. The azulene derivatives, such as $66 \mathbf{a}$ and $66 \mathbf{b}$, are prepared by the reaction of electrophiles such as iodomethane, methyl chloroformate, $N, N^{\prime}$-carbonyldiimidazole and $N, N^{\prime}$-thiocarbonyldiimidazole, with the bis(thiolate) obtained by the treatment of 65 with $\mathrm{LiAlH}_{4}$ (Scheme 21) [38]. $\mathrm{PPh}_{3}$-mediated desulfuration of pentathiepin 65, followed by the reaction with DMAD produces azuleno-1,4-dithiin 68 in $56 \%$ yield. The reaction of 65 with $\mathrm{Pd}\left(\mathrm{PPh}_{3}\right)_{4}$ gives the extremely unstable palladium complex $69(6 \%)$, which is immediately converted to a binuclear complex.

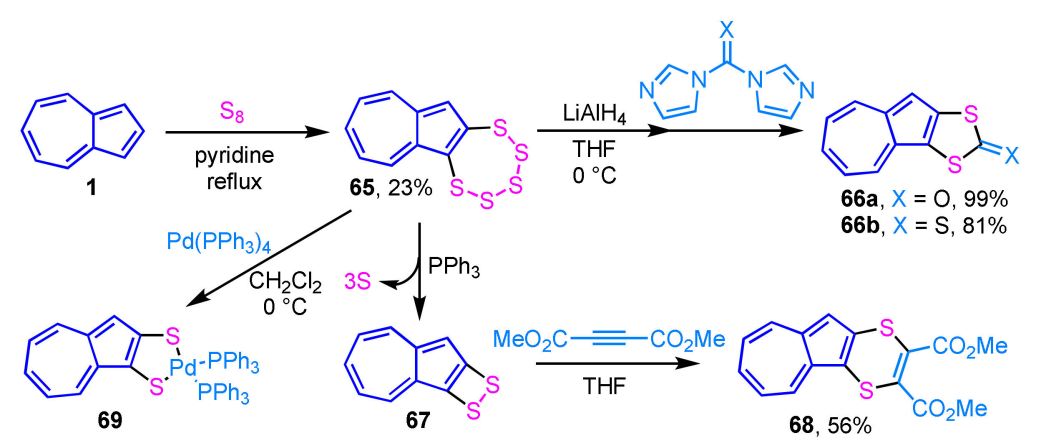

Scheme 21. Synthesis and reactivity of azulenopentathiepin 65.

Starting from the dithiocarbonate derivative $66 \mathrm{a}$, which was obtained by the reaction described above, the synthesis of azulene-fused TTFs $70 \mathbf{a}$ and $\mathbf{7 0 \mathbf { b }}$ was achieved by the same group (Scheme 22) [39]. The condensation reaction of dithiocarbonate 66a with vinylene trithiocarbonate or ethylenedithio derivative in triethyl phosphite generates azulene-fused TTFs $70 \mathrm{a}$ and $70 \mathrm{~b}$ in moderate yields $(22 \%$ and $49 \%$, respectively). The redox behavior of the azulene-fused TTFs was also investigated by cyclic voltammetry (CV). 


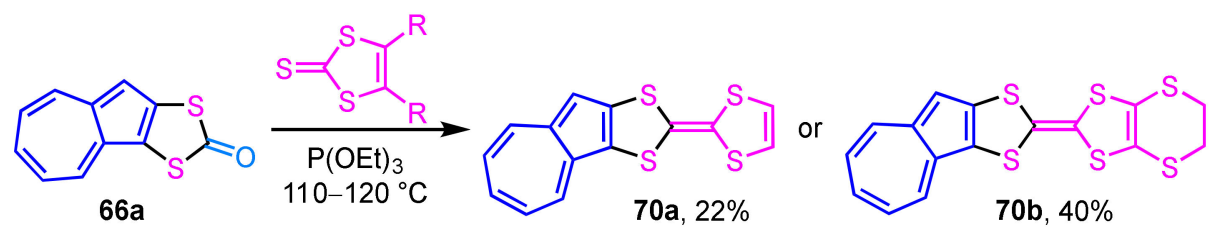

Scheme 22. Synthesis of azulene-fused TTFs 70a and 70b by the condensation reaction.

Synthesis of the donor-acceptor-type extended TTFs 73 incorporated into cross-conjugated systems is achieved by the sequential [2 +2$]$ cycloaddition-retroelectrocyclization reaction of electron-rich butadiyne with tetracyanoethylene followed by TTF (Scheme 23) [40]. Butadiyne $\mathbf{7 1}$ gives tetracyanobutadiene $\mathbf{7 2}$ by the reaction with tetracyanoethylene, which is then converted to $\mathbf{7 3}$ by the cycloaddition with TTF. The UV/Vis spectrum of $\mathbf{7 3}$ shows a strong and broad absorption band in the visible region $\left(\lambda_{\max }=471\right)$ owing to the overlapping of the charge-transfer $(\mathrm{CT})$ absorption bands arising from both azulene and 1,2-bis(1,3-dithiol-2-ylidene)ethane donors to the tetracyanobutadiene acceptor unit. In the electrochemical analysis of 73 , a reversible one-stage two-electron oxidation wave and a two-stage reduction wave are observed in $\mathrm{CV}$.

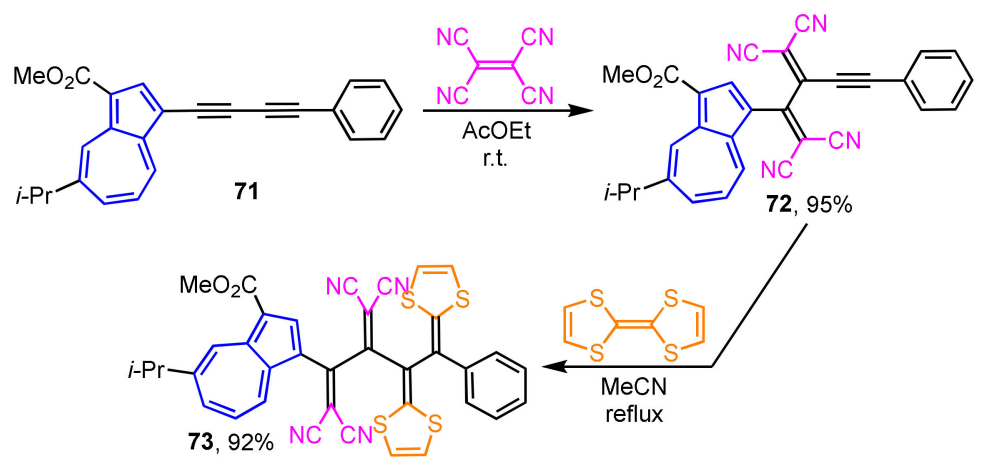

Scheme 23. The synthesis of TCNE/TTF double adduct 73 by sequential $[2+2]$ cycloaddition-retroelectrocyclization reaction.

Cross-coupling by the palladium-catalyzed $\mathrm{C}-\mathrm{H}$ bond activation applies to the preparation of azulene-substituted TTFs (Scheme 24). 2-Chloroazulene derivative 74 reacts with TTF in the presence of $\mathrm{Pd}(\mathrm{OAc})_{2}$ and $\mathrm{P}(t-\mathrm{Bu})_{3} \cdot \mathrm{HBF}_{4}$ as a ligand to generate tetra(2-azulenyl)TTF $75(57 \%)$, along with tri(2-azulenyl)TTF 76 (9\%) [41]. Although parent TTF exhibits a two-stage reversible oxidation wave, the CV experiments on 75 display one quasi-reversible wave under the electrochemical oxidation conditions owing to the overlapping of the first wave with the following irreversible waves. The spectroelectrochemical measurements of $\mathbf{7 5}$ exhibit significant spectral changes under the electrochemical reduction conditions. 


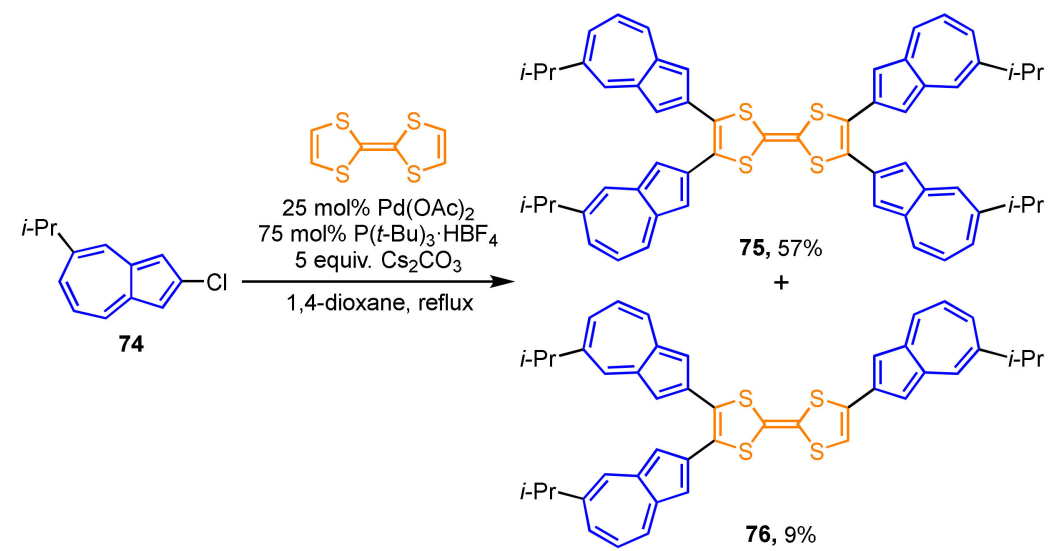

Scheme 24. Synthesis of tetra(2-azulenyl)TTF 75 by the palladium-catalyzed $\mathrm{C}-\mathrm{H}$ bond activation reaction.

Thiophene-fused azulenes sometimes exhibit a different reactivity from that of usual azulene derivatives. Thiophene-fused $1,1^{\prime}$-biazulene derivative 78 is obtained by the reaction of azuleno[1,2-b] thiophene (77) with NIS, instead of the presumed iodoazulene derivative (Scheme 25) [42]. NIS is commonly known as an iodination reagent, but it may act as an oxidant in this case. Although the longest absorption band of $\mathbf{7 8}$ displayed larger absorption coefficients than that of $\mathbf{7 7}$, the absorption maxima are observed at almost the same wavelength region. The similarity of the absorption maxima of $\mathbf{7 7}$ and $\mathbf{7 8}$ suggests less effective conjugation due to the low planarity of the two azulene rings of $\mathbf{7 8}$. Compound 77 undergoes a sequential cycloaddition-reverse electron cyclization with DMAD under high temperature reaction conditions $\left(200{ }^{\circ} \mathrm{C}\right)$ to give thiophene-fused heptalene 79 in $60 \%$ yield [43]. The presence of bond alternation and the nonaromatic nature of $\mathbf{7 9}$ are revealed by single-crystal X-ray crystallographic analysis.

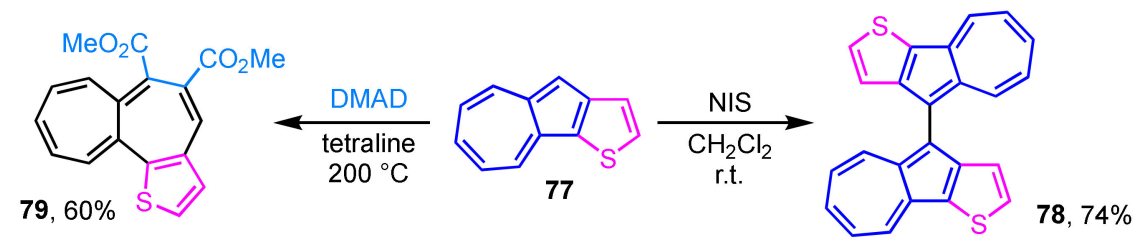

Scheme 25. Reactivity of azuleno[1,2-b]thiophene (77).

Photochromism is a phenomenon that is attracting a lot of attention in the field of materials science. Construction of an azulene-based photochromic system was reported by Uchida and co-workers (Scheme 26) [44]. The synthesis of $\mathbf{8 1}$ is accomplished by Suzuki-Miyaura cross-coupling reaction of $\mathbf{8 0}$ with a 3-thienylboronic acid ester. The light irradiation from excitation of $\mathbf{8 1}$ at $\lambda_{\mathrm{ex}}=313 \mathrm{~nm}$ generates new absorption bands at $\lambda_{\max }=495 \mathrm{~nm}$ and at around $\lambda_{\max }=700 \mathrm{~nm}$ owing to the formation of the ring-closed system $\mathbf{8 2}$.

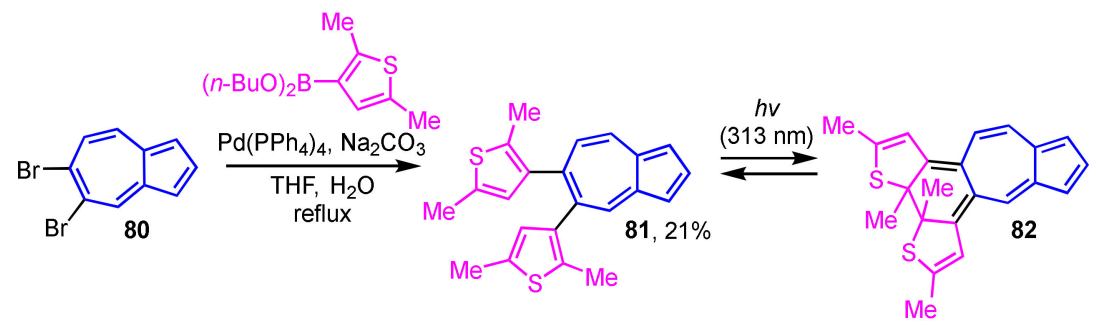

Scheme 26. Synthesis of 5,6-di(3-thienyl)azulene derivative 81 by Suzuki-Miyaura cross-coupling reaction. 
Some azulene derivatives are expected to be components of organic semiconductors due to their unique electronic properties. The synthesis of 2-arylazulene derivatives connected by 2,2'-bithiophene 84 and thieno[3,2-b]thiophene 85 by Suzuki-Miyaura cross-coupling reaction was reported by Katagiri et al. (Scheme 27) [45]. The single-crystal X-ray analysis revealed the herringbone packing in the crystal structure of 84 and 85 . Compounds 84 and 85 are aligned almost perpendicular to the substrate in the film form and show the characteristics of an OFET having a hole mobility.

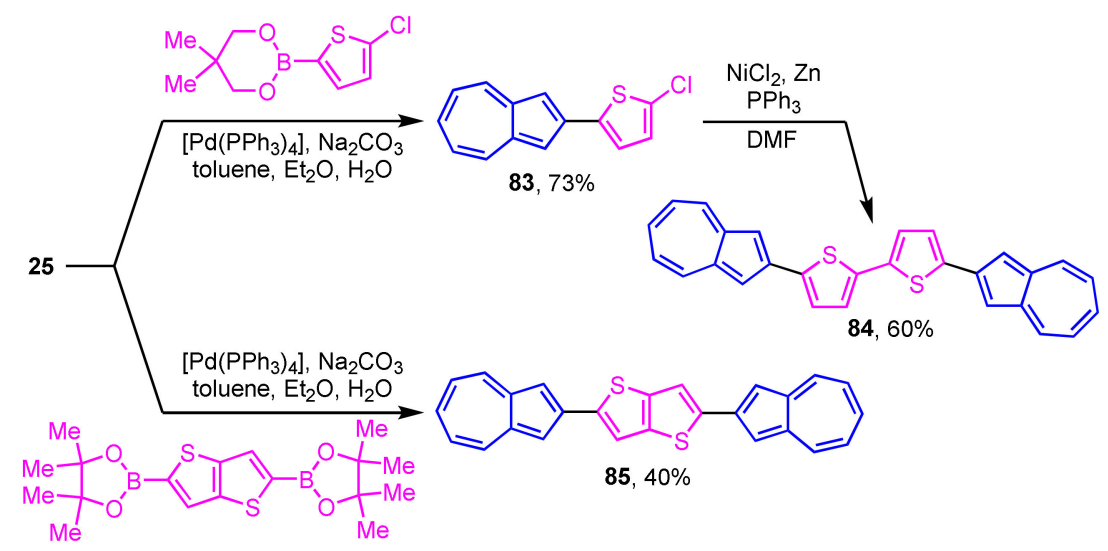

Scheme 27. Synthesis of 2,2'-bithiophene 84 and thieno[3,2-b]thiophene 85 substituted by 2-azulenyl groups.

The synthesis of 1,3-di(2-thienyl)azulene derivatives $\mathbf{8 8 a}$ and $\mathbf{8 8 b}$ with an extended $\pi$-conjugated system has been reported. Bromination of $\mathbf{8 6}$ at the 5-position of the two 2-thienyl moieties can be enabled with NBS to give 87 , which reacts with tri-n-butylaryltin reagents in the presence of tetrakis(triphenylphosphine)palladium(0) and triphenylarsine ligand to afford $88 \mathbf{a}$ and $\mathbf{8 8 b}$ in $61 \%$ and $56 \%$ yields, respectively (Scheme 28) [46]. The UV/Vis spectrum of $\mathbf{8 8 a}$ and $\mathbf{8 8 \mathbf { b }}$ in $\mathrm{CHCl}_{3}$ shows the characteristic absorption band of azulene derivatives, but protonation of $\mathbf{8 8 a}$ and $\mathbf{8 8 \mathbf { b }}$ with trifluoroacetic acid shows noticeable changes of their absorption spectra both in the visible and near-IR regions.

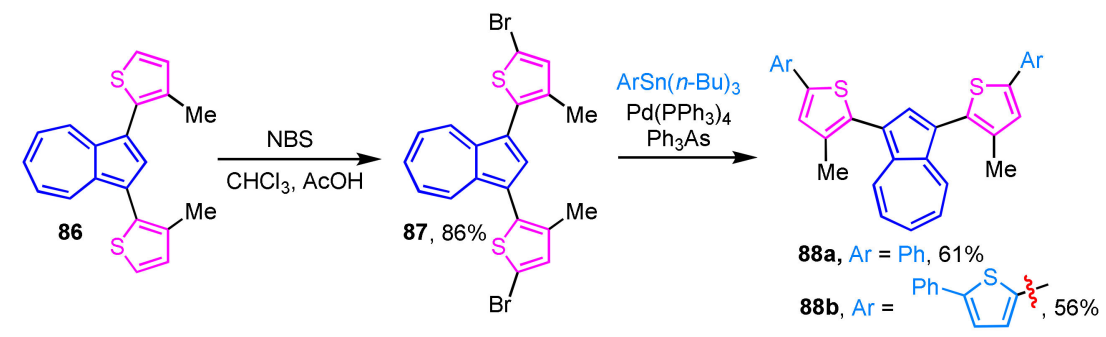

Scheme 28. Synthesis of 1,3-di(5-aryl-2-thienyl)azulenes $\mathbf{8 8 a}$ and $\mathbf{8 8 b}$ by Stille cross-coupling reaction.

Direct preparation of 2-thienylazulene derivatives by employing the $\mathrm{C}-\mathrm{H}$ bond activation reaction has also been reported (Scheme 29) [47]. The reaction of 2-chloroazulene derivative 89 with 3,4-ethylenedioxythiophene (EDOT) in the presence of $\mathrm{Pd}(\mathrm{OAc})_{2}, \mathrm{PCy}_{3} \cdot \mathrm{HBF}_{4}$, pivalic acid (PivOH), and $\mathrm{K}_{2} \mathrm{CO}_{3}$ to produce 2-thienylazulene derivative 90 in $81 \%$ yield, which reacts further with 89 to afford symmetric 2,5-di(2-azulenyl)thiophene derivative 91 in $88 \%$ yield. 


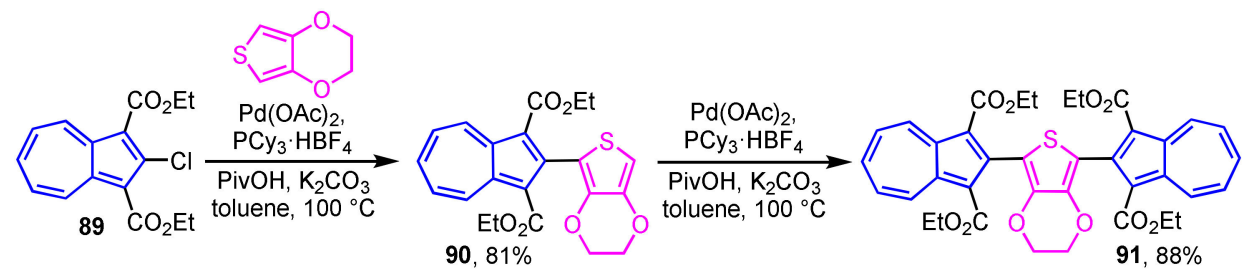

Scheme 29. Synthesis of 2-(2-thienyl)azulene 90 and 2,5-di(2-azulenyl)thiophene 91 by palladium-catalyzed $\mathrm{C}-\mathrm{H}$ bond activation reaction.

The synthesis of photochromic 1-(2-thienyl)azulene-based diarylethene derivatives 92a and $\mathbf{9 2 b}$ has been achieved by Nica and co-workers utilizing Suzuki-Miyaura cross-coupling reaction (Scheme 30) [48]. Compound 93 was also synthesized via deformylation by the treatment with pyrrole in acetic acid using $\mathbf{9 2} \mathbf{b}$ as a starting material. Photocyclization of compounds $\mathbf{9 2 a} \mathbf{9} \mathbf{9 2} \mathbf{b}$, and 93 in $\mathrm{CH}_{2} \mathrm{Cl}_{2}$ takes place by irradiating the light at $\lambda_{\mathrm{ex}}=405 \mathrm{~nm}$ with the color change of the solution from greenish-yellow to blue-purple due to form ring-closing derivatives $94 \mathbf{9}-\mathbf{9 4 c}$.

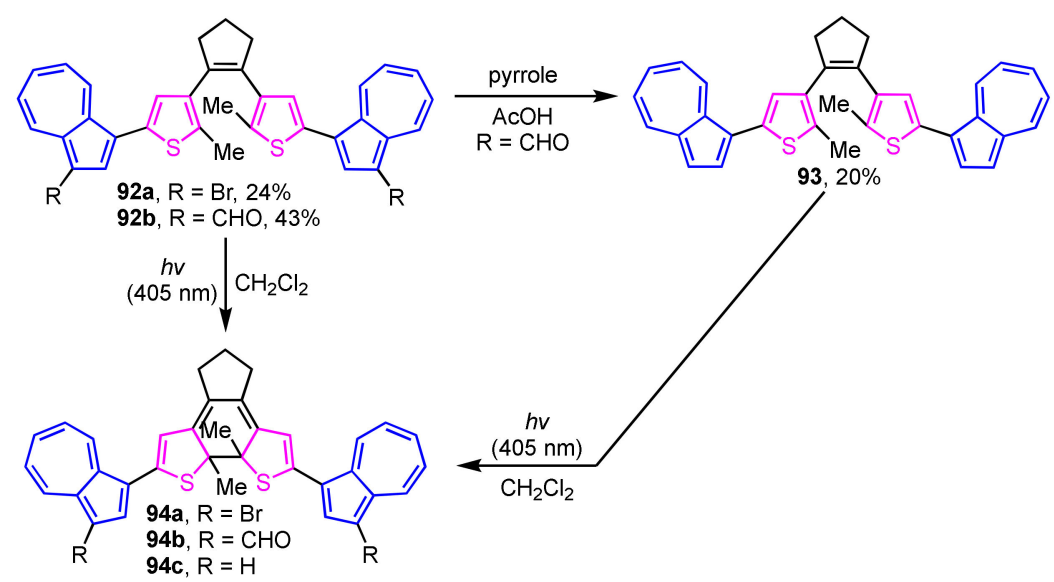

Scheme 30. Photoinduced ring-closure reaction of dithienylethenes 92a, 92b, and 93.

Hawker et al. reported the Stille cross-coupling reaction of 4,7-dibromoazulene 95 with 2-thienyltin reagents under the microwave irradiation conditions to give 4,7-di(2-thienyl)azulene derivatives 96a-96c (Scheme 31) [49,50]. In the UV/Vis spectrum of these 4,7-di(2-thienyl)azulene derivatives, a weak absorption band arising from the azulene skeleton is observed in $\mathrm{CH}_{2} \mathrm{Cl}_{2}$, while a strong absorption band is appeared at around $\lambda_{\max }=500 \mathrm{~nm}$ in $\mathrm{CF}_{3} \mathrm{CO}_{2} \mathrm{H}$. Compound 96a shows a strong fluorescence at $\lambda_{\mathrm{FL}}=573 \mathrm{~nm}$ in $\mathrm{CF}_{3} \mathrm{CO}_{2} \mathrm{H}$, which is not observed in $\mathrm{CH}_{2} \mathrm{Cl}_{2}$. 


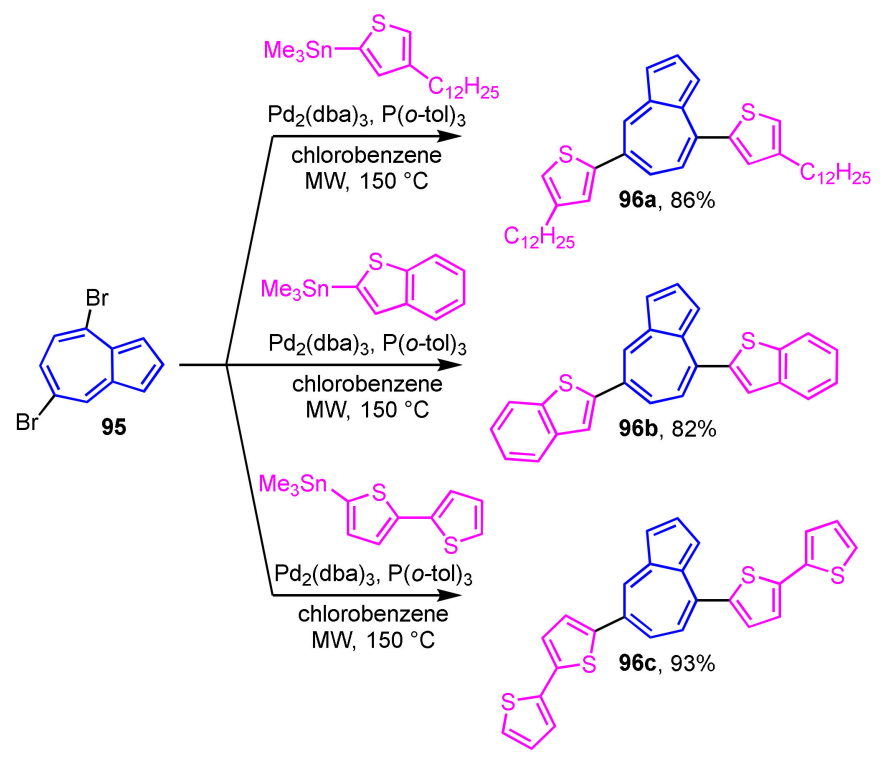

Scheme 31. Synthesis of 4,7-di(2-thienyl)azulenes 96a-96c by Stille cross-coupling reaction under the microwave irradiation conditions.

Lewis et al. reported the preparation of azulene-containing dyes $99 a$ and $99 b$ and evaluated their performance as dye-sensitized solar cells (DSSCs) [51]. The synthesis of these azulene dyes 99a and 99b was accomplished in four to five steps, including the cross-coupling reaction of 1-azulenylsulfonium salts 37 and 97 with the corresponding thiophene-2-boronic acid following Knoevenagel condensation (Scheme 32). These azulene dyes 99a and 99b are characterized as sensitizers in DSSCs concerning their electrochemical nature and crystal structure.

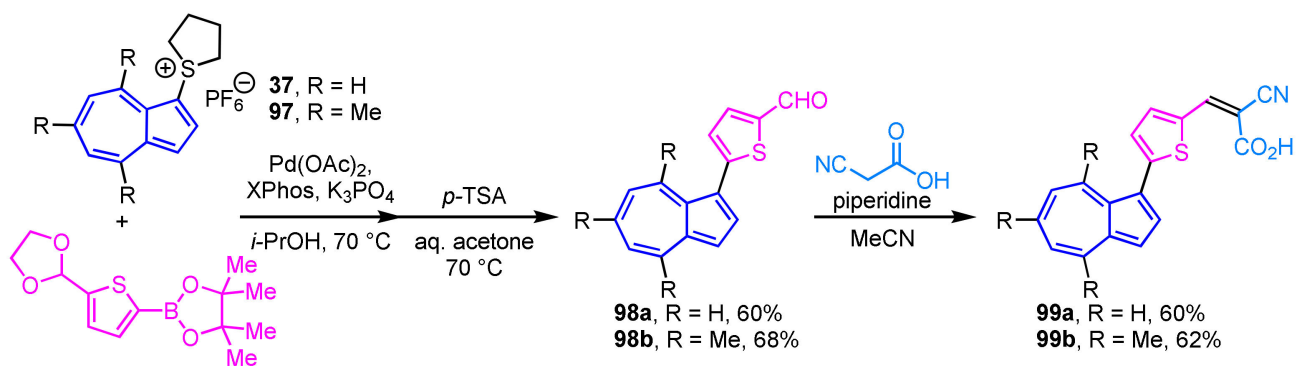

Scheme 32. Synthesis of azulene-containing dyes 99a and 99b via Knoevenagel condensation of 1-(5-formyl-2-thienyl)azulenes $98 \mathbf{a}$ and $\mathbf{9 9 b}$.

A method for the preparation of azuleno[2,1-b]thiophene derivatives 101 with aryl substituent at the thiophene moiety was reported [52]. In this synthetic procedure, azuleno[2,1-b]thiophene derivatives $\mathbf{1 0 1}$ can be obtained in one step by the reaction of readily available azulenyl alkynes $\mathbf{1 0 0}$ with elemental sulfur (Scheme 33). The azuleno[2,1-b]thiophene 101 with a phenyl substituent is converted to 102 by decarboxylation with $100 \% \mathrm{H}_{3} \mathrm{PO}_{4}$. Both the UV/Vis measurements and DFT calculations show that the optical properties of azuleno[2,1-b]thiophenes are significantly affected by the electronic nature of the aryl substituents on the thiophene moiety. The decarboxylated derivative 102 in $\mathrm{CH}_{2} \mathrm{Cl}_{2}$ displays a similar absorption band in the visible region to that of the corresponding ester derivative, while the addition of $\mathrm{CF}_{3} \mathrm{CO}_{2} \mathrm{H}$ to the solution shows a pronounced color change, so-called halochromism, due to the protonation of the 5-membered ring of azuleno[2,1-b]thiophene to produce a tropylium ion substructure. 


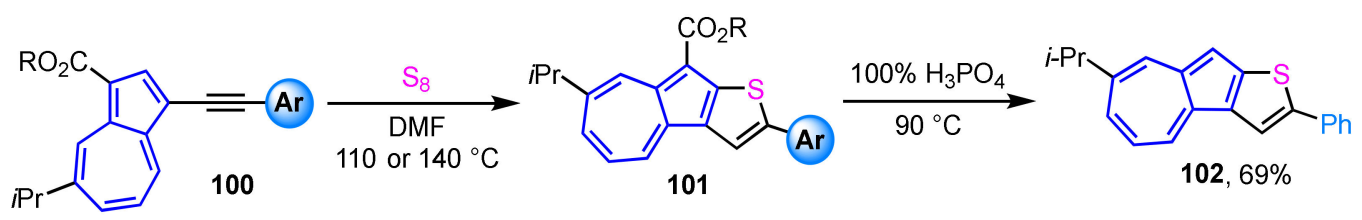

Scheme 33. Synthesis of azuleno[2,1-b]thiophenes 101 by the reaction of azulenyl alkynes with elemental sulfur and preparation of $\mathbf{1 0 2}$ by following decarboxylation with $100 \% \mathrm{H}_{3} \mathrm{PO}_{4}$.

\subsection{Azulene Derivatives with N-Containing 5- and 6-Membered Heterocycles}

The compounds with pyrrole and indole skeletons can be found in many natural products, bioactive substances, and pharmaceuticals. Several reports on the synthesis of pyrrole and indole derivatives connected to the azulene ring have been published.

Abe et al. have achieved two-step synthesis of pyrrole-fused azulene derivatives using 1-iodo-2-acetoaminoazulene derivatives as a starting material (Scheme 34) [53]. Sonogashira cross-coupling reaction of iodo derivative 103 with the corresponding alkynes yielded 2-acetylamino-1-ethynylethynyazulenes 104a and 104b in good yields. Cyclization of 104a in the presence of $\mathrm{PdCl}_{2}\left(\mathrm{PPh}_{3}\right)_{2}$ and $\mathrm{Et}_{3} \mathrm{~N}$ as a base in DMF gives azuleno[2,1-b]pyrrole 105 in $72 \%$ yield accompanied by the elimination of the acetyl group on the nitrogen atom.

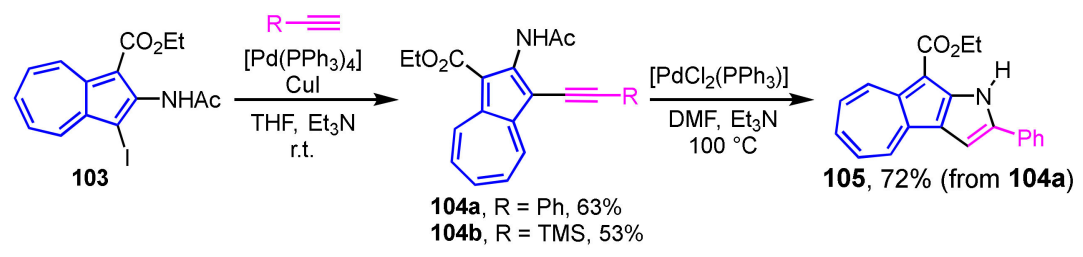

Scheme 34. Synthesis of azuleno[2,1-b]pyrrole 105 by palladium-catalyzed cyclization of 104a.

Tsukada and co-workers have demonstrated the synthesis of (2-azulenyl)(1-aza-2-azulenyl)amines 108a-108c containing azulene and 1-azaazulene linkage via a nitrogen atom (Scheme 35) [54]. The Hartwig-Buchwald reaction of 2-aminoazulene 106 with 2-halo-1-azaazulenes 107a-107c was employed for the synthesis of 108a-108c. As a result of the investigation of several conditions, the catalytic system using $\mathrm{PdCl}_{2}(\mathrm{dppf}) / \mathrm{BINAP}$ in THF provides the best results.

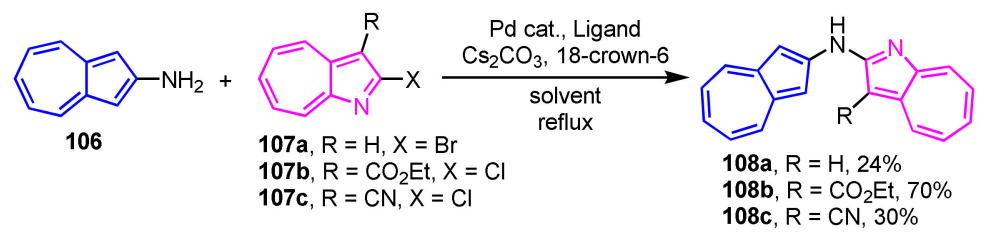

Scheme $35 . \quad$ Synthesis of (2-azulenyl)(1-aza-2-azulenyl)amines 108a-108c by

Hartwig-Buchwald reaction.

Vilsmeier-Haack-type reaction of azulene derivatives with 2-indolinone was conducted in the presence of $\mathrm{Tf}_{2} \mathrm{O}$ affords 1-(indol-2-yl)azulenes (Scheme 36) [55]. In this research, the substituent at the 6-position of the azulene ring was found to affect the reactivity, significantly. The reaction of 1 and 109 produces mono-substituted products $110 \mathrm{a}$ and $110 \mathrm{c}$, whereas $20 \mathrm{a}$ gives $110 \mathrm{~b}$ (64\% yield) as the main product along with the di-substituted product 111 (13\% yield). 


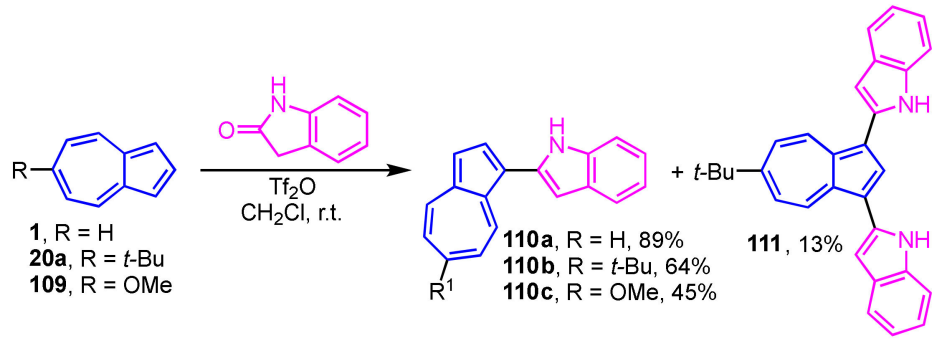

Scheme 36. Synthesis of 1-(indol-2-yl)azulenes 110a-110c and 111 by Vilsmeier-Haack-type reaction.

The synthesis of tetraarylpyrroles $\mathbf{1 1 3}$ with a 1-azulenyl substituent has been accomplished by cyclization of benzoin with 1-azulenyl ketones $\mathbf{1 1 2}$ with various aryl groups at the $\alpha$-position in the presence of ammonium acetate as the nitrogen source for the pyrrole ring (Scheme 37) [56]. The yield of the reaction depends largely on the electronic properties of the aryl group substituted at the $\alpha$-position of the ketones 112. The origin of the absorption bands observed in the UV/Vis spectra of the tetraarylpyrroles $\mathbf{1 1 3}$ with a 1-azulenyl substituent was clarified by time-dependent density functional theory (TD-DFT) calculations.

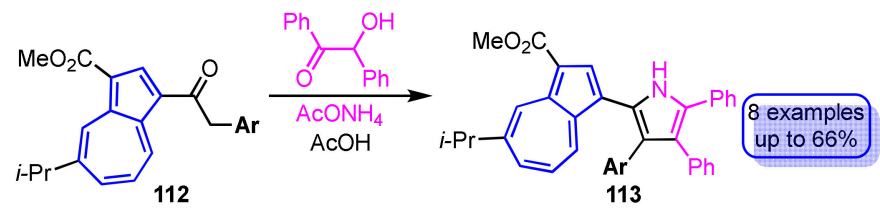

Scheme 37. Synthesis of tetraarylpyrroles 113 by cyclization of benzoin with 1-azulenyl ketones 112.

A synthetic route to pyrrolo[3,2-b]pyrroles $115 \mathbf{a}$ and $\mathbf{1 1 5} \mathbf{b}$ with two 5-azulenyl or 6-azulenyl groups have been developed by Gryko et al. (Scheme 38) [57]. In this method, pyridine-substituted pyrrolo[3,2-b]pyrroles 114a and $\mathbf{1 1 4} \mathbf{b}$ are converted, in three steps, to azulene-substituted pyrrolo[3,2-b]pyrroles $\mathbf{1 1 5 a}$ and $\mathbf{1 1 5 b}$ via Ziegler-Hafner method, i.e., successive $N$-arylation, ring-opening with dimethylamine, and the reaction with cyclopentadienide ion. The optical properties of azulene-substituted pyrrolo[3,2-b]pyrroles $\mathbf{1 1 5 a}$ and $\mathbf{1 1 5 b}$ were evaluated in terms of absorption spectra and quantum chemical calculations using TD-DFT.

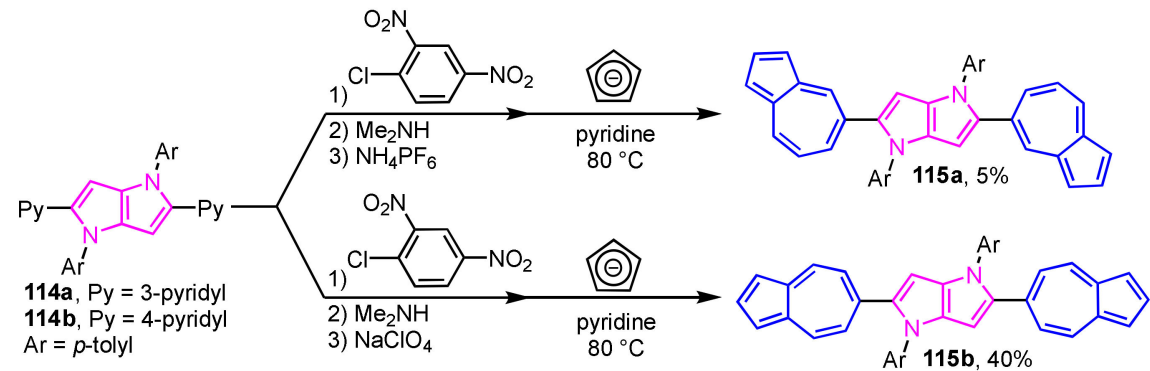

Scheme 38. Synthesis of azulene-substituted pyrrolo[3,2-b]pyrroles 115a and 115b via Ziegler-Hafner method.

In 2019, Wang et al. reported two methods for the synthesis of pyrrole-substituted azulene derivatives via the reaction of guaiazulene (9) with methylglyoxal in common (Scheme 39). The first of the two procedures is the three-component domino reaction of $\mathbf{9}$, methylglyoxal and enaminones under the acid catalyzed conditions to obtain 3-(guaiazulen-3-yl)dihydro- $1 H$-indol-4(5H)-ones 116 in good yields (80-90\%) [58]. 


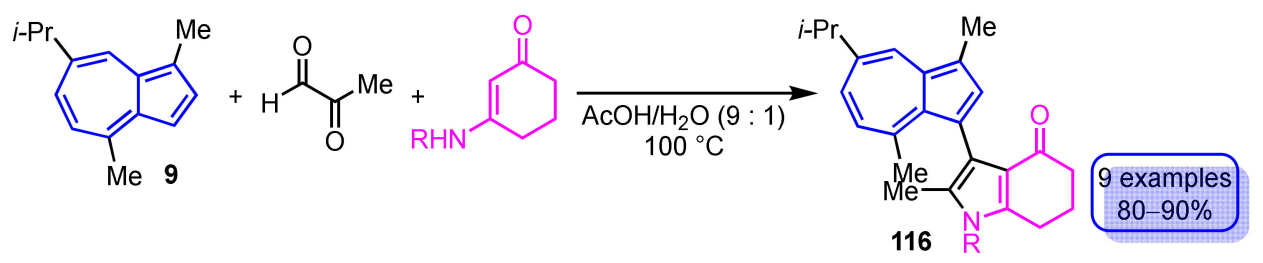

Scheme 39. Synthesis of 3-(guaiazulen-3-yl)dihydro- $1 H$-indol-4(5H)-ones $\mathbf{1 1 6}$ by the three-component domino reaction.

In another method, the synthesis of 3-(guaiazulen-3-yl)pyrroles $\mathbf{1 1 8}$ has been achieved by the Paal-Knorr reaction of 3-acetyl-4-(guaiazulen-3-yl)hexane-2,5-dione (117), which is obtained by the reaction of 9 , methylglyoxal, and acetylacetone in the presence of acetic acid via primary amines (Scheme 40) [59]. Both of these synthetic methods provide a facile method for the preparation of pyrrole-substituted azulene derivatives.

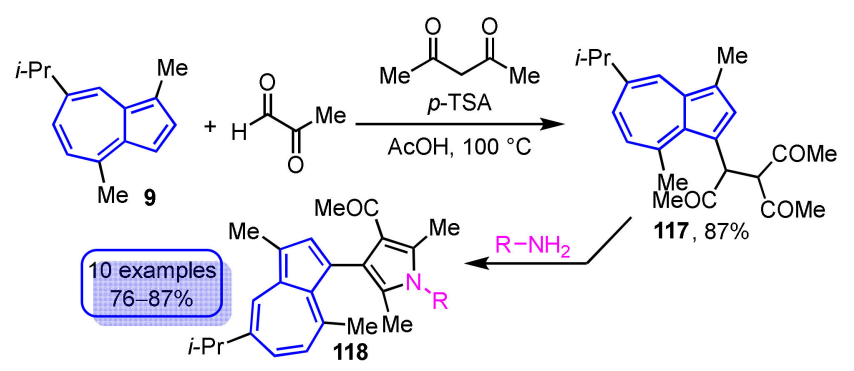

Scheme 40. Synthesis of 3-(guaiazulen-3-yl)pyrroles 118 via Paal-Knorr reaction of 3-acetyl-4-(guaiazulen-3-yl)hexane-2,5-dione (117).

The synthesis of azulene-fused tryptanthrin, i.e., azuleno $\left[1^{\prime}, 2^{\prime}: 4,5\right]$ pyrrolo[2,1-b]quinazoline6,14-dione (121), has recently been reported (Scheme 41) [60]. The synthesis of $\mathbf{1 2 1}$ is accomplished by the condensation reaction of azuleno[2,1-b]pyrrole-2,3-dione (120a), which is prepared by the reaction of 2-aminoazulene (106) with oxalyl chloride, with isatoic anhydride in the presence of sodium hydride or diisopropyl ethylamine (DIPEA) as a base. The ester derivative 120b provides no desired product due to the decomposition under the similar reaction conditions. Halogenation reaction of $\mathbf{1 2 1}$ using NBS and NIS results in high yields of 12-halo derivatives. However, even though the reaction of NBS smoothly proceeds at room temperature, the reaction with NIS requires a relatively high reaction temperature (refluxing in 1,2-dichloroethane). The redox properties of the new azulene-fused tryptanthrins are evaluated by spectroscopic and voltammetric analyses.

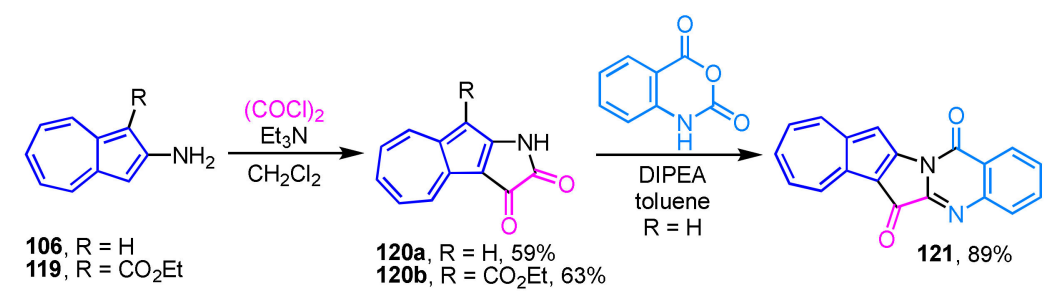

Scheme 41. Synthesis of azuleno[1' $\left., 2^{\prime}: 4,5\right]$ pyrrolo[2,1-b]quinazoline-6,14-dione (121).

\subsection{Azulene Derivatives with O-Containing 5-Membered Heterocycles}

Although there are not many reports for the synthesis of azulene derivatives containing furans and their derivatives in the molecule, various approaches such as cross-coupling and intramolecular cyclization have been applied to the preparation of such compounds.

$\mathrm{Wu}, \mathrm{Ku}$, and their co-workers have reported the two-step synthesis of 2-(3-furyl)azulene derivatives $\mathbf{1 2 4} \mathbf{a}$ and $\mathbf{1 2 4 b}$ [61]. The diketone derivatives $123 a$ and $\mathbf{1 2 3} b$ are prepared by the reaction of $\mathbf{1 2 2} a$ and 
122b with 4'-methoxyphenacyl bromide in the presence of $\mathrm{CaH}_{2}$ in DMF. Compounds 124a and 124b can be obtained by Paal-Knorr reaction, i.e., treatment with $p$-TSA in DMF, in 67\% and 70\% yields, respectively (Scheme 42).

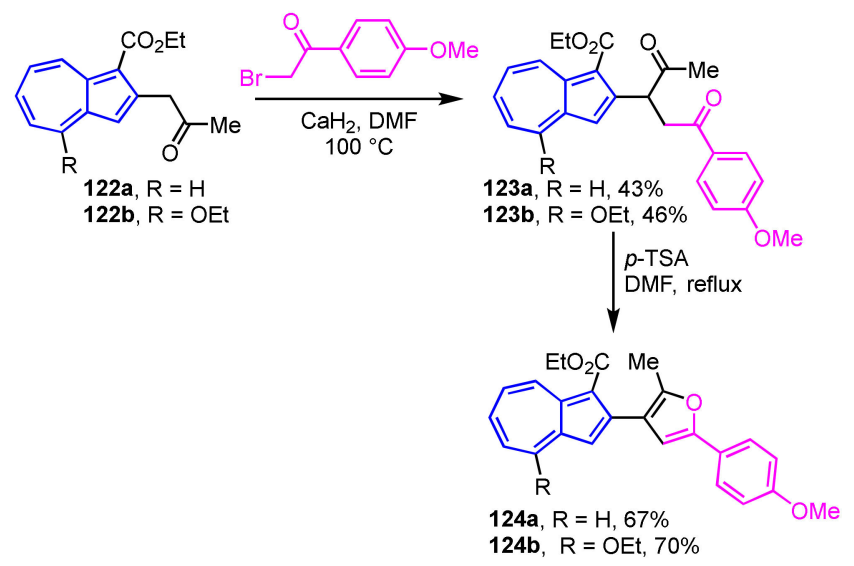

Scheme 42. Synthesis of 2-(3'-furyl)azulenes 124a and $124 \mathrm{~b}$ via Paal-Knorr reaction.

The synthesis of 3-(2-furyl)guaiazulene derivatives 126 by phosphine-mediated intermolecular cyclization of 3-(3-phenyl-2-cyanopropenoyl)guaiazulenes 125 with benzoyl chlorides is demonstrated by Wang and $\mathrm{Xu}$ et al. (Scheme 43) [62]. This reaction provides 3-(2-furyl)guaiazulene derivatives 126 in excellent yields when the substituent $\mathrm{R}^{2}$ on the benzoyl chloride is an electron-donating group, while the yield of the products is slightly lower when the substituent $\mathrm{R}^{2}$ has an electron-withdrawing nature.

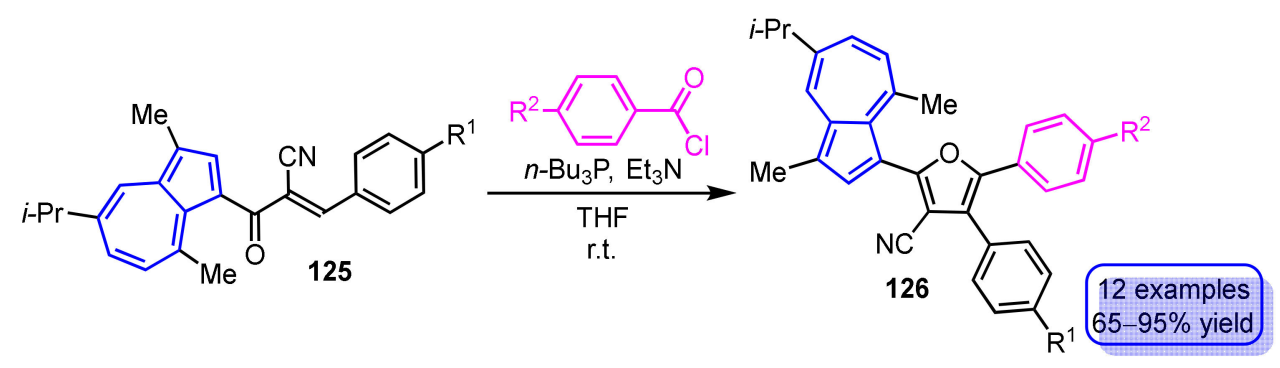

Scheme 43. Phosphine-mediated synthesis of 3-(2-furyl)guaiazulene derivatives 126.

The synthesis and optical properties of $\pi$-extended derivatives 129 and $\mathbf{1 3 0}$ with two 2-(2-furyl)azulene units connected to diketopyrrolopyrrole have been reported by Hawker et al. (Scheme 44) [63]. The two regioisomers 129 and 130 are obtained in 69\% and 84\% yields, respectively, by the Suzuki-Miyaura cross-coupling reaction of 1- and 2-azulenylboronates 128 and 43 with 3,6-bis(5-bromo-2-furyl)pyrrolo[3,4-c]pyrrole-1,4-dione (127) in a mixed solvent of toluene and DMF by microwave irradiation. 


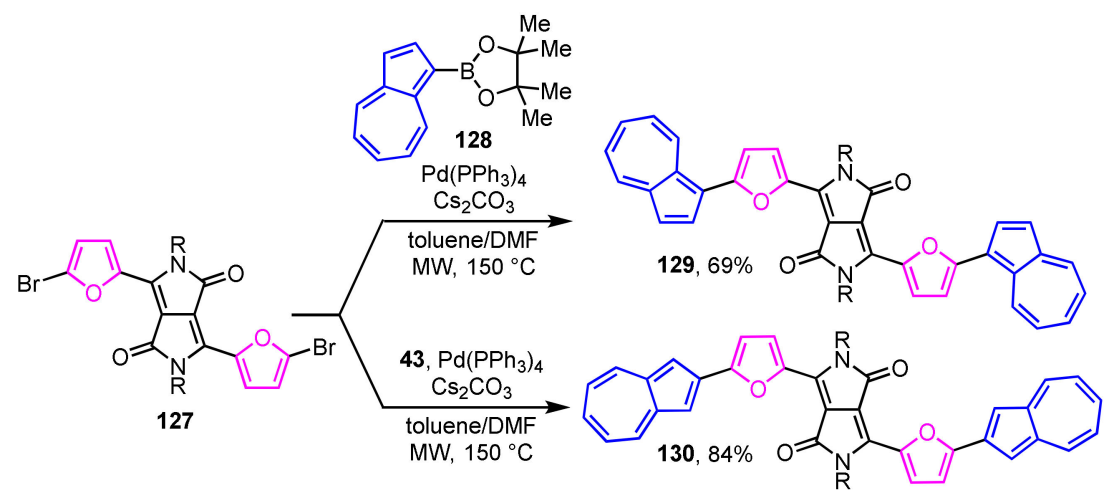

Scheme 44. Synthesis of 1- and 2-(2-furyl)azulenes 129 and $\mathbf{1 3 0}$ with a diketopyrrolopyrrole by microwave-assisted Suzuki-Miyaura cross-coupling reaction.

2-(1-Azulenyl)benzofurans 132a-132c are obtained in one pot under the Sonogashira-Hagihara reaction conditions by the reaction of 1-ethynylazulene derivatives 131a-131c, which are prepared from 1-iodoazulenes 130a-130c as starting materials, with 2-iodophenol (Scheme 45) [35]. By contrast, the reaction of 130a-130c with 2-ethynylphenol under the similar conditions affords 2,3-di(1-azulenyl)benzofurans 133a-133c along with 132a-132c as a byproduct. The structures of these compounds were clarified by single-crystal X-ray structure analysis.

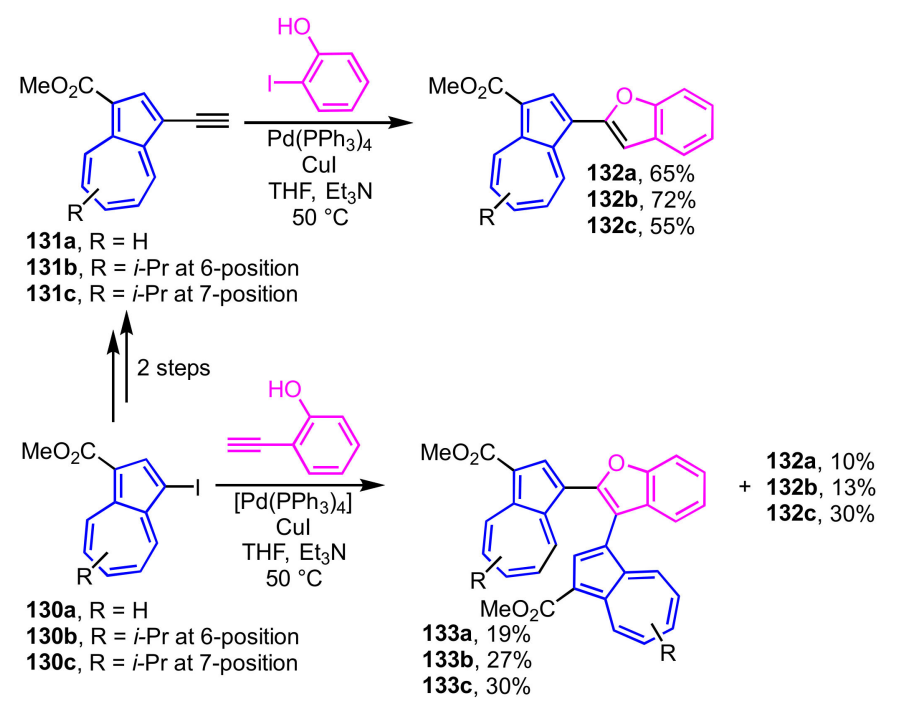

Scheme 45. Synthesis of 2-(1-azulenyl)benzofurans 132a-132c and 2,3-di(1-azulenyl)benzofurans 133a-133c under Sonogashira-Hagihara reaction conditions.

The reaction of 3-(1-azulenyl)propargyl alcohols 134 with tetracyanoethylene produces 2-aminofuran derivatives $\mathbf{1 3 5}$ cross-conjugated by azulene-ring in excellent yields (Scheme 46) [64]. The formation of the 2-amino furan ring is believed to derive from the $[2+2]$ cycloaddition-retroelectrocyclization of alkynes with tetracyanoethylene and subsequent nucleophilic addition of the hydroxy group to one of the cyano groups. The 2-aminofuran $\mathbf{1 3 5}$ can be converted into 6-aminopentafulvenes $\mathbf{1 3 6}$ and 6,6-diaminopentafulvenes $\mathbf{1 3 7}$ in moderate to excellent yields by treatment with an excess of primary and secondary amines. Diels-Alder reaction of $\mathbf{1 3 5}$ with maleimides affords phthalimide derivatives 139 cross-conjugated with an azulene ring in one pot and without the isolation of presumed [4 +2] cycloadducts 138 [65]. Even though 139 does not exhibit luminescence in $\mathrm{CH}_{2} \mathrm{Cl}_{2}$, remarkable fluorescence is observed in a mixed solvent of $\mathrm{CH}_{2} \mathrm{Cl}_{2}$ and $\mathrm{CF}_{3} \mathrm{CO}_{2} \mathrm{H}$. 


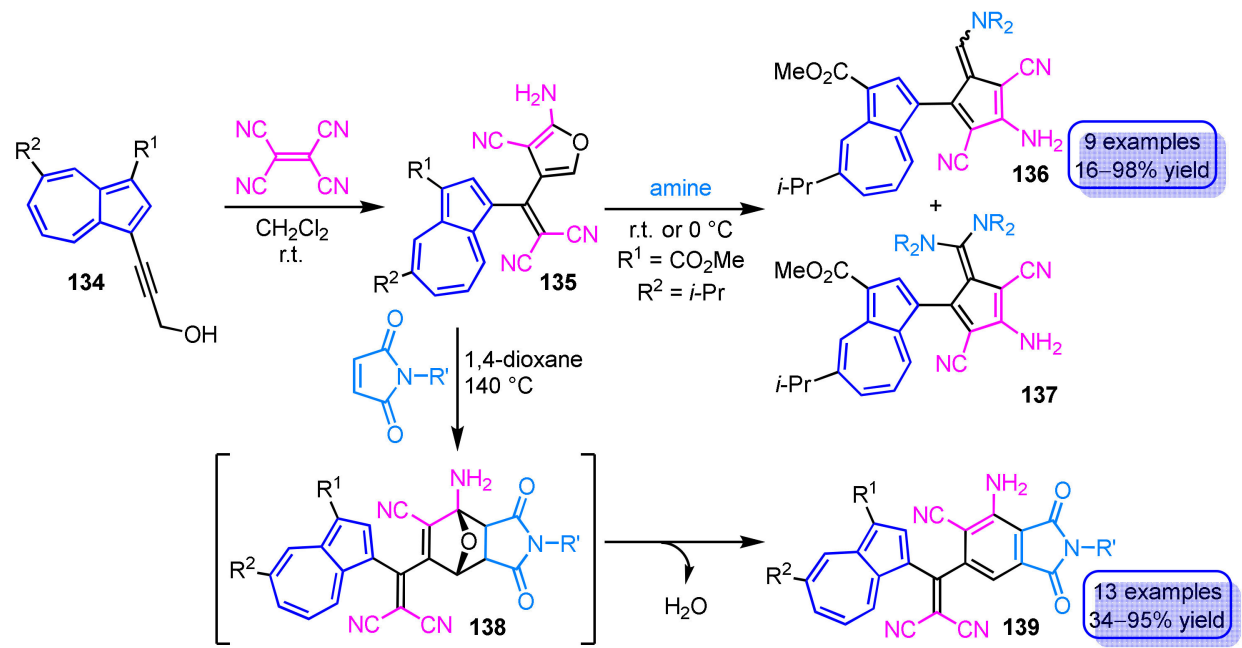

Scheme 46. Synthesis of 2-aminofurans 135 by the reaction of 3-(1-azulenyl)propargyl alcohols 134 with tetracyanoethylene and conversion of 135 to 6-aminopentafulvenes 136, 137 and phthalimides 139.

\subsection{Azulene Derivatives with Other Ring Heterocycles}

In addition to the aforementioned, preparation of various azulene derivatives with a variety of heterocycles have been reported. An overview of the derivatives with other 5-membered ring heterocycles is given below.

Matano et al. reported the synthesis and optical properties of phosphole derivative $\mathbf{1 4 1}$ substituted with two 2-azulenyl groups (Scheme 47) [66]. The synthesis is performed under Stille cross-coupling conditions by the reaction of 2,5-bis(tributylstannyl)phosphole $\mathbf{1 4 0}$ and 2-iodoazulene (25) using $\mathrm{Pd}_{2}(\mathrm{dba})_{3}$, (2-furyl $)_{3} \mathrm{P}$, and $\mathrm{CuI}$ as catalysts, giving the target compound 141 in $52 \%$ yield. Compound 141 in $\mathrm{CH}_{2} \mathrm{Cl}_{2}$ shows an absorption wavelength maximum at $\lambda_{\max }=481 \mathrm{~nm}$ in UV/Vis spectrum, while no emission is displayed from $\mathbf{1 4 1}$ in the same way as the usual azulene derivatives.

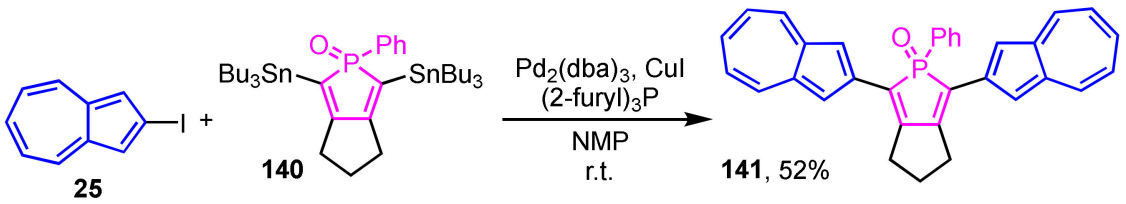

Scheme 47. Synthesis of 2,5-di(2-azulenyl)phosphole 141 by Stille cross-coupling reaction.

Although preparation of 2,6-diaminoazulenes has been known to be difficult, an efficient method for their synthesis by aromatic nucleophilic substitution reactions $\left(\mathrm{S}_{N} \mathrm{Ar}\right)$ was reported in 2015 (Scheme 48) [67]. The $S_{N} A r$ reaction of 2-amino-6-bromoazulene derivative $\mathbf{1 4 2}$ with cyclic amines such as pyrrolidine, piperidine, and morpholine at $130{ }^{\circ} \mathrm{C}$ in a sealed tube affords the corresponding 2,6-diaminoazulene derivatives 145a-145c in excellent yields. Alternatively, the amination reaction at lower temperature is achieved by the treatment of trifluoroacetamide derivative 143, which is obtained by the reaction of $\mathbf{1 4 2}$ with trifluoroacetic anhydride, with amines at room temperature to give the corresponding 2,6-diaminoazulenes 144a-144c. The trifluoroacetamide substituent of $\mathbf{1 4 5 a - 1 4 5 c}$ is transformed into an amino group by deprotection with $\mathrm{K}_{2} \mathrm{CO}_{3}$ in $\mathrm{EtOH}$ to form 145a-145c. 


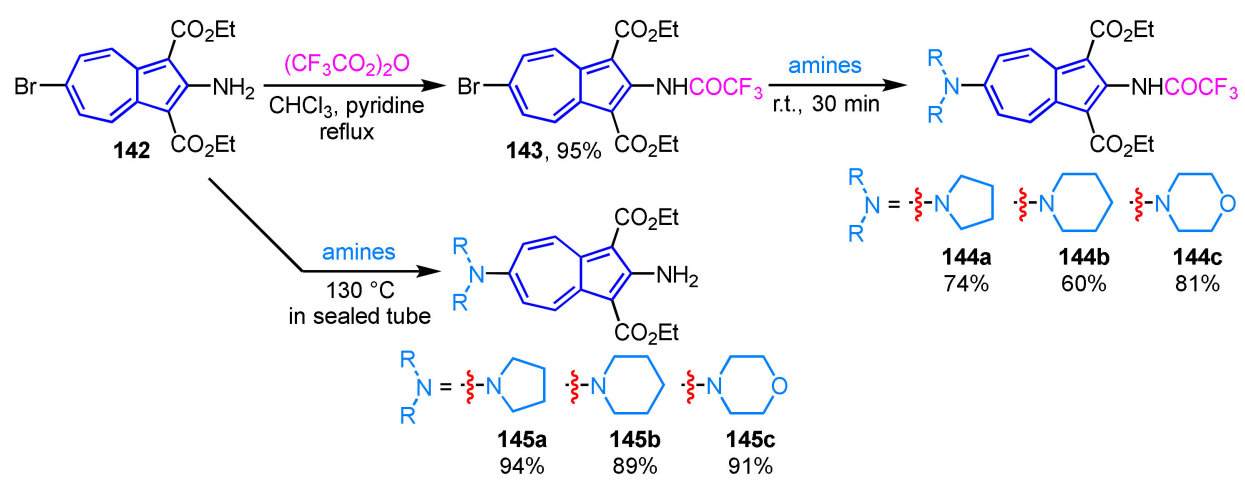

Scheme 48. Synthesis of 2,6-diaminoazulenes $145 a-145 c$ by $S_{N} A r$ reaction with amines.

Similar to the aforementioned reaction, the reaction of 6-bromoazulene 146 with two ester groups with amines yields the corresponding 6-aminoazulene derivatives 147 in good to excellent yields (Scheme 49) $[68,69]$. The electrophilic substitution reaction of a derivative with a pyrrolidine substituent at the 6-position with bromine provides 2-bromo-6-pyrrolidinylazulene derivative 148 . Since the introduction of halogen functional group at the 2-position of azulene derivatives by electrophilic substitution reactions is usually difficult, this method is one of the preferable methods for the functionalization of azulenes. The two ester groups of the 6-aminoazulene derivatives $\mathbf{1 4 7} \mathrm{can}$ be removed by decarboxylation reaction using $100 \% \mathrm{H}_{3} \mathrm{PO}_{4}$ to afford parent 6-aminoazulenes 149 in excellent yields.

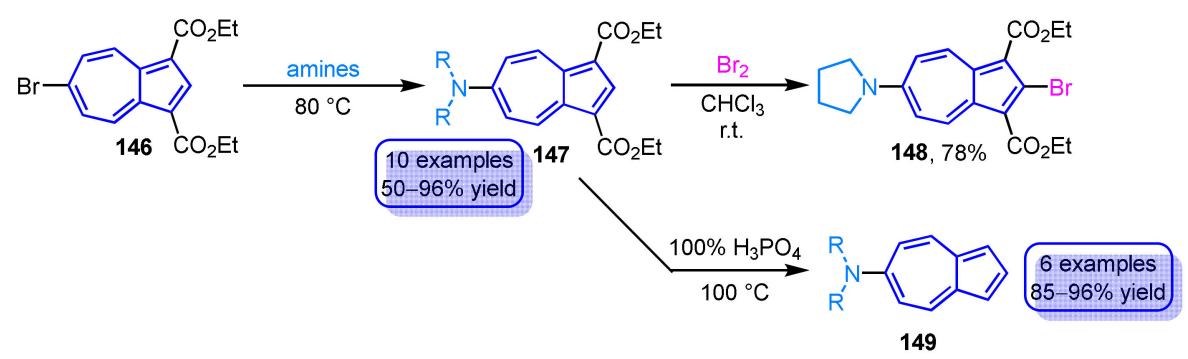

Scheme 49. Synthesis and reactivity of 6-aminoazulene derivatives 147 .

In 2013, Wakabayashi et al. reported the synthesis and coordination behavior of 7-aza-4,10-dithia-1-oxacyclododecane (azathiocrown) derivative $\mathbf{1 5 1}$ substituted by azulene ring at the 6-position (Scheme 50) [70]. The synthesis of 151 is accomplished by the one-pot condensation-cyclization reaction of iminium salt 150 with cyclopentadienide ion, i.e., by Ziegler-Hafner method. Compound 151 shows a color change from red to purple when $\mathrm{Ag}^{+}$ ion $\left(\mathrm{AgClO}_{4}\right)$ is added in an acetone solution. This change in coloration is believed to be caused by the interaction of $\mathrm{Ag}^{+}$ions with the nitrogen atoms of azathiocrown ether, based on the ${ }^{1} \mathrm{H}$ NMR experiments.

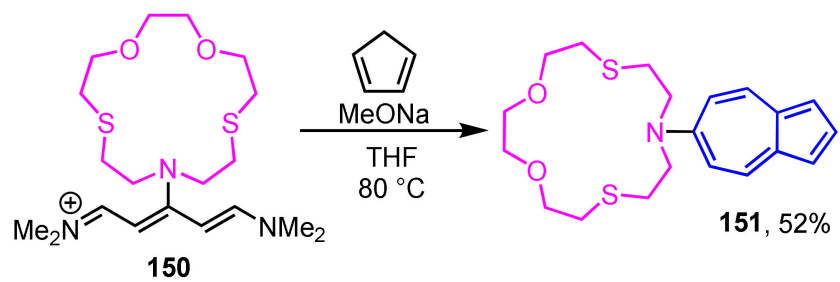

Scheme 50. Synthesis of azathiocrown derivative 151 substituted by azulene ring at the 6-position. 
Wakamiya, Scott, and their colleagues reported the synthesis and properties of extended $\pi$-electron molecules in which the oxygen-bridged triarylamines are connected to an azulene ring, for application in perovskite solar cells [71]. The precursor, 1,3,5,7-tetraborylazulene 152, is obtained by iridium-catalyzed Hartwig-Miyaura borylation of azulene (1) with bis(pinacolato)diboron with $38 \%$ as isolated yield (Scheme 51) [72]. Synthesis of the target molecule, tetrasubstituted azulene 153, is achieved by multiple Suzuki-Miyaura cross-coupling of $\mathbf{1 5 2}$ with mono-brominated oxygen-bridged triarylamine in $58 \%$ yield. The performance of tetrasubstituted azulene $\mathbf{1 5 3}$ as a hole transport material for perovskite solar cells (power conversion efficiency $=16.5 \%$ ) was found to be superior to the current HTM standard, spiro-OMeTAD.

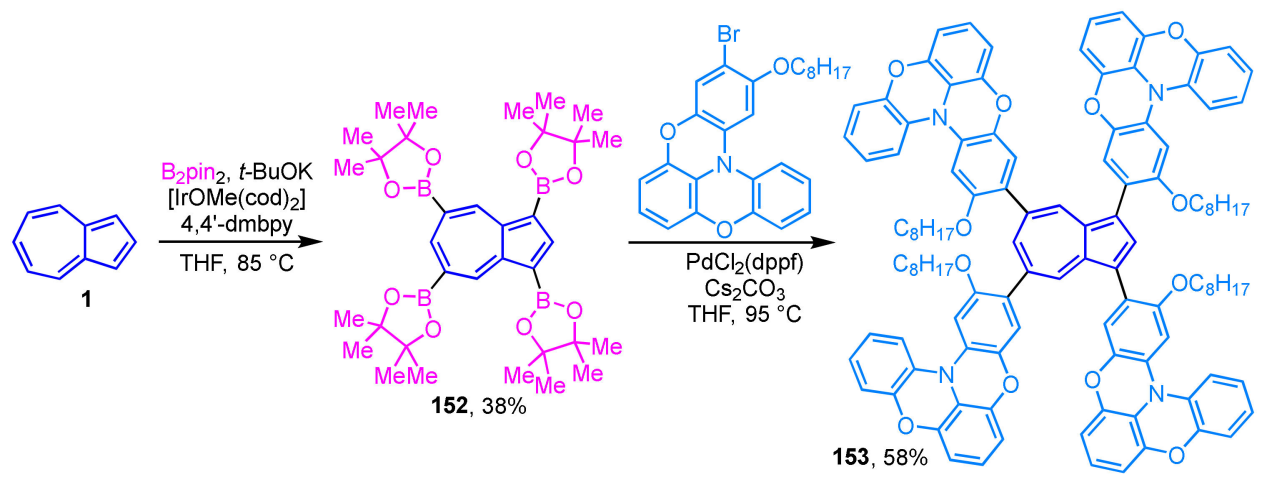

Scheme 51. Synthesis of tetrasubstituted azulene 153 by multiple Suzuki-Miyaura cross-coupling of 152.

Murafuji et al. demonstrated the synthesis of azulene-substituted cyclic boronic acid esters 156a-156e by the reaction of 2-azulenylboronic acid 155 with several diols (Scheme 52) [73]. The reaction of 2-azulenyl lithium $\mathbf{1 5 4}$ with trimethyl borate yields a boronic acid ester, which is then hydrolyzed by acid to give 2-azulenylboronic acid 155. Cyclic esterification of 2-azulenylboronic acid $\mathbf{1 5 5}$ with several diols are completed within $3 \mathrm{~h}$ in most cases, whereas the reaction with catechol requires $42 \mathrm{~h}$ to complete the reaction due to the low nucleophilicity of the diol.

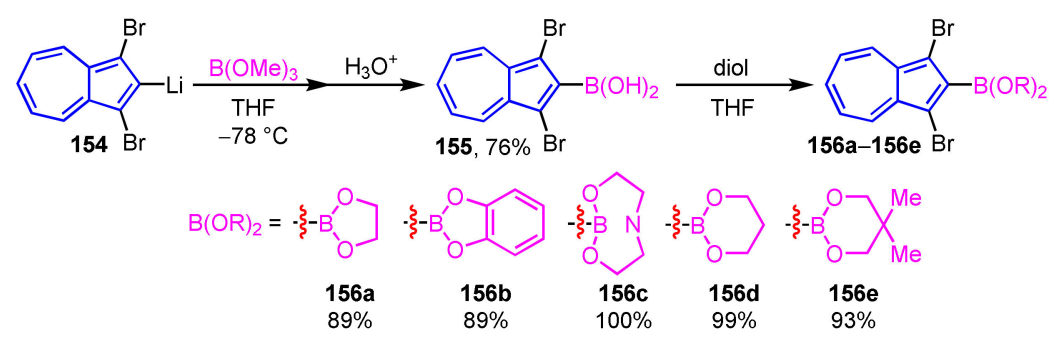

Scheme 52. Synthesis of 2-azulenylboronic acid esters 156a-156e by the reaction of 2-azulenylboronic acid 155.

Since the elevated concentrations of reactive oxygen species (ROS) and reactive nitrogen species (RNS) in living organisms are associated with a variety of diseases including cancer and cardiovascular disease, much attention has been paid to the development of methods to detect these active species in living cells. Lewis et al. reported AzuFluor 483-Bpin 157 that exhibits fluorescence upon reaction with ROS and RNS (Scheme 53) [74]. The synthesis of AzuFluor 483-Bpin 157 is accomplished by the palladium-catalyzed borylation of the corresponding 2-amino-6-bromoazulene. The staining of various living cells with compound 157 shows remarkable luminescence due to the conversion to 158 by the reaction with ROS and RNS in the cells. Therefore, compound 157 is expected to apply to the direct detection of ROS and RNS in the living cells. 


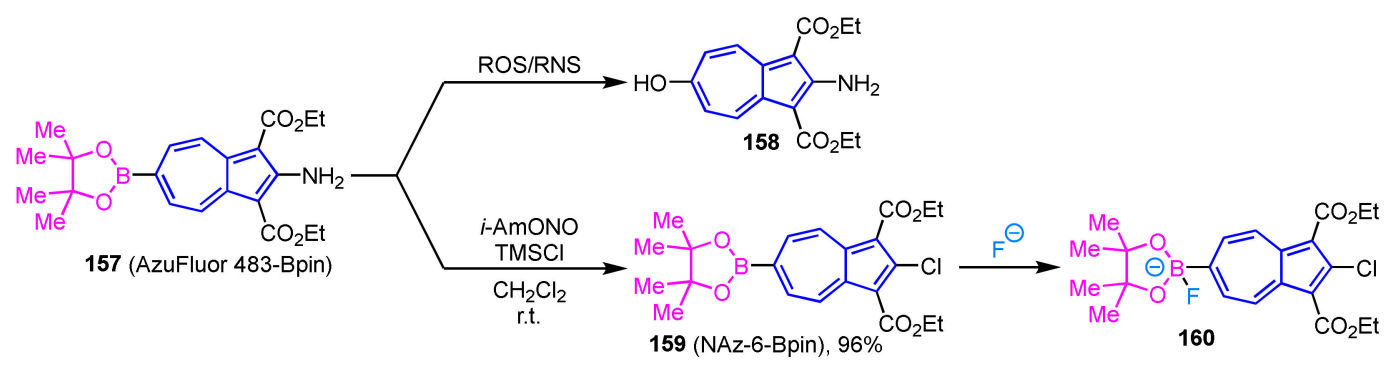

Scheme 53. The reaction of an azulene-based fluorescent probe (AzuFluor 483-Bpin 157).

The same group reported the synthesis of an azulene derivative (NAz-6-Bpin 159) as a potential fluoride detection agent in water and the evaluation of its ion selectivity (Scheme 53) [75]. The synthesis of NAz-6-Bpin 159 has been achieved by the Sandmeyer reaction of 157 using TMSCl and isoamyl nitrite. Since NAz-6-Bpin $\mathbf{1 5 9}$ can be used in a mixed solvent of water and ethanol without surfactants, this compound has potential applications for the detection of fluoride in drinking water in the field.

\section{Synthesis of Azulene-Fused Imide Derivatives}

Phthalimide and other aromatic imide derivatives have attracted much interest in the fields of materials chemistry and pharmaceutical sciences so that various synthetic methods have been reported.

Gao and colleagues have prepared diimide derivatives based on 2,2'-biazulene and demonstrated their optical and electrochemical properties (Scheme 54) [76]. 2,2'-Biazulene-1,1',3,3'-tetracarboxylic diimides (BAZDIs 162 and 164) are synthesized by aminolysis of acid anhydrides 161 and 163, followed by dehydration with $\mathrm{SOCl}_{2}$. The X-ray crystal structures, optical and electrochemical properties, and charge transport properties of $\mathbf{1 6 2}$ and $\mathbf{1 6 4}$ are examined. The results of various measurements reveal that BAZDIs 162 and 164 have relatively higher LUMO energies and narrower band gaps than those of the corresponding perylene diimides.
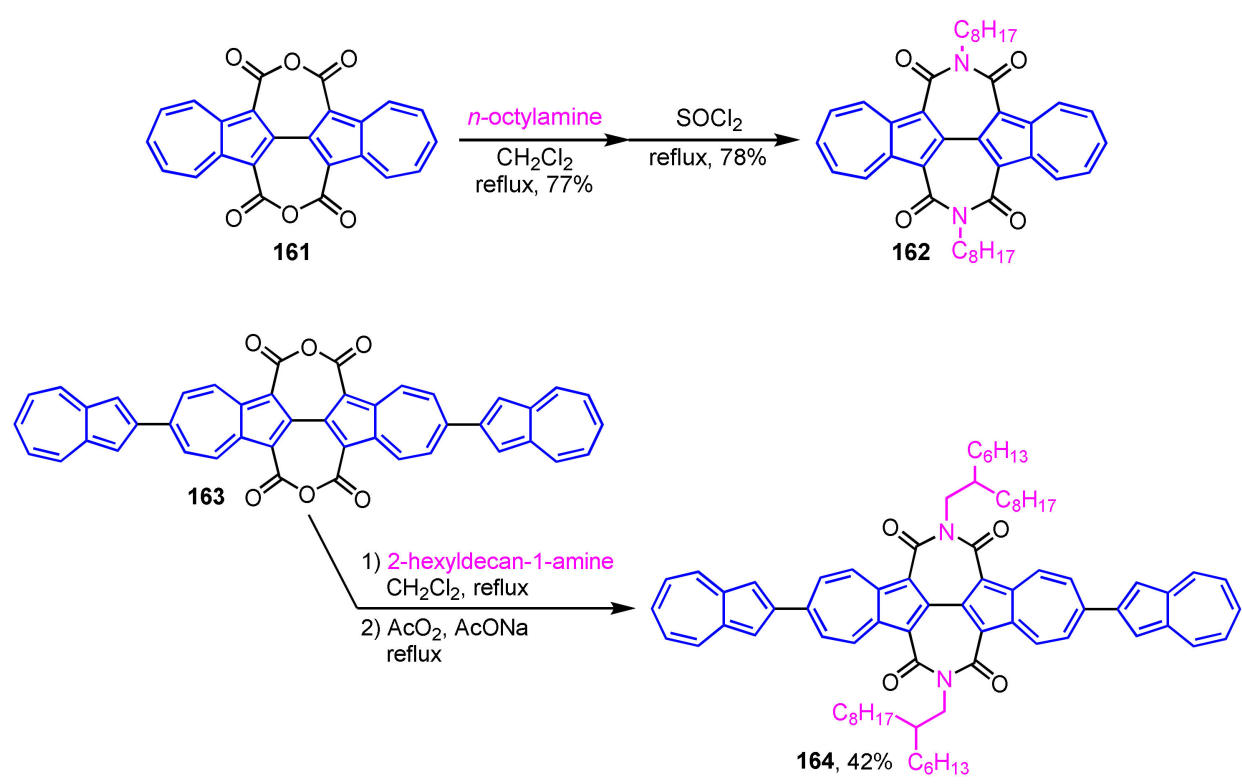

Scheme 54. Synthesis of 2,2'-biazulene-1,1',3,3' -tetracarboxylic diimides (BAZDIs 162 and 164).

The same group found that conjugated polymers 166 and 167 embedded with 2,2'-biazulene diimide units act as high-performance OFETs (Scheme 55) [77]. The thermal stability of polymers 166 and 167 is examined by thermogravimetric analysis (TGA), and these polymers did not decompose until the temperature was raised above $400{ }^{\circ} \mathrm{C}$. Conjugated polymers 166 and 167 represent excellent 
OFET performance with high-electron mobility, and especially polymer 167 was found to be one of the best unipolar $n$-type polymers reported to date.

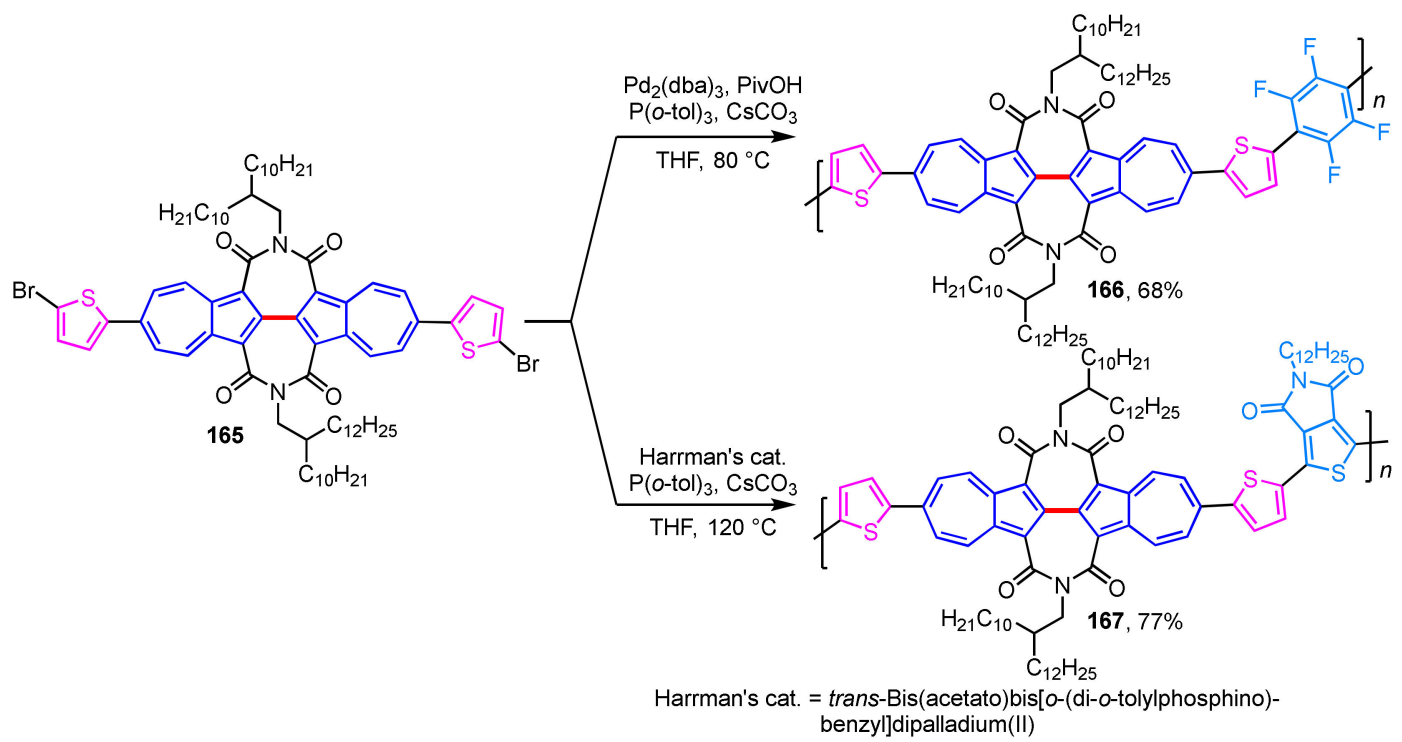

Scheme 55. Synthesis of 2,2'-biazulene-based conjugate polymers 166 and 167.

A novel tetraazulene-fused tetracenediimide (TA-fused TDI 170) was prepared and evaluated using various experimental measurements and theoretical calculations by Tani and co-workers (Scheme 56) [78]. The synthesis of $\mathbf{1 7 0}$ is accomplished by the Suzuki-Miyaura cross-coupling reaction of 43 with tetrabromonaphthalene diimide to give 169, following the Scholl reaction of 169 with DDQ at low temperature $\left(-60^{\circ} \mathrm{C}\right)$. Fusing azulene rings to the TDI core, $\mathbf{1 7 0}$ shows a small HOMO-LUMO gap and intramolecular $\mathrm{CT}$ interaction based on an effective $\pi$-electron conjugation. TA-fused TDI $\mathbf{1 7 0}$ also shows unique properties such as absorption in the near-infrared region which appeared in the absorption spectrum, a four-step reversible reduction process observed in the CV experiments, and $n$-type semiconductivity. These outcomes suggest that TA-fused TDI $\mathbf{1 7 0}$ has potential application in photonics as an electronic material.

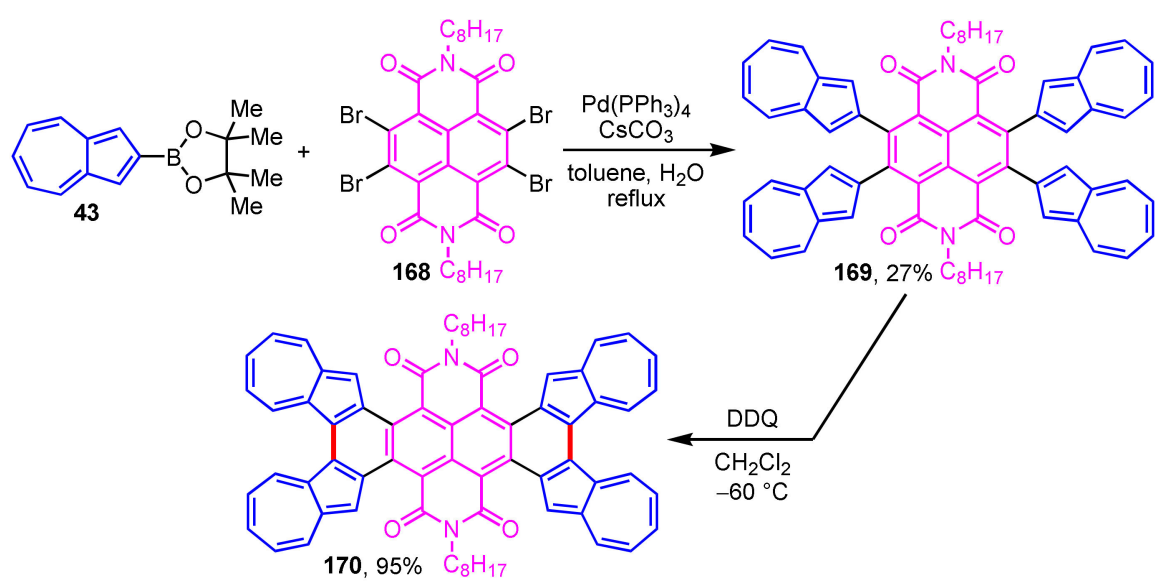

Scheme 56. Synthesis of tetraazulene-fused tetracenediimide (TA-fused TDI 170).

Recently, the synthesis of phthalimide-fused azulene derivatives $\mathbf{1 7 2}$ was accomplished by condensation of 1,2-diformylazulene derivatives with maleimides in the presence of phosphine catalysts (Scheme 57) [79]. Various phosphine catalysts and the reaction solvents were investigated to find that phthalimide-fused azulene derivatives $\mathbf{1 7 2}$ were obtained in the highest yields when 
triphenylphosphine was used as a catalyst in DMF as the solvent. The ester group of $\mathbf{1 7 2}$ can be removed by decarboxylation with $100 \% \mathrm{H}_{3} \mathrm{PO}_{4}$, yielding 173 in quantitative yield. The addition of trifluoroacetic acid to the solution of $\mathbf{1 7 3}$ indicates a marked color change, so-called halochromism. Furthermore, blue-colored luminescence is observed when the acidic solution of $\mathbf{1 7 3}$ is irradiated at $\lambda_{\mathrm{ex}}=365 \mathrm{~nm}$, even though no emission is observed in common organic solvents. This luminescence could be ascribed to that from the phthalimide moiety because protonation by trifluoroacetic acid produces a tropylium ion $[\mathbf{1 7 3}+\mathrm{H}]^{+}$, which reduces the contribution of the azulene form that may quench the emission.

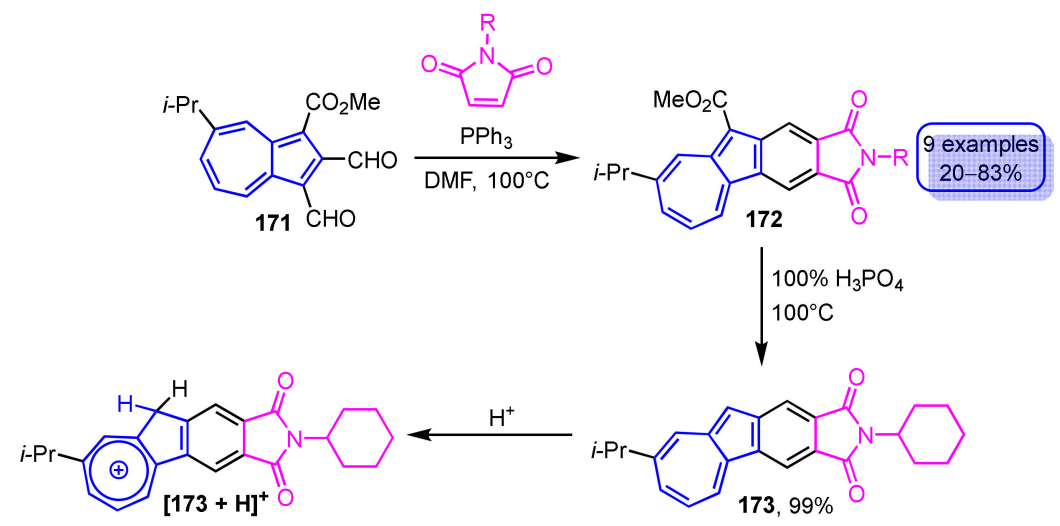

Scheme 57. Synthesis and protonation of phthalimide-fused azulene derivative 173.

\section{Synthesis of Azulene Derivatives Incorporated with Porphyrinoid}

Azulenes with porphyrinoid are classified into three structures as shown in Figure 1. Azuliporphyrin, one of the core-modified porphyrins in which an azulene has replaced a pyrrole subunit, was first reported by Lash in 1997 [80]. Azulene-substituted and azulene-fused porphyrins were reported by Osuka and co-workers [81,82]. There were many reports of azuliporphyrins and related compounds over the last two decades [83-86]. The azulene subunit interrupts the conjugative pathway, which suggests a nonaromatic character (I in Figure 1). However, the zwitterionic resonance structure II leads to full macrocyclic aromaticity as an $18 \pi$-porphyrinoid. This section surveys the synthetic methods of azuliporphyrin, ring-expanded/contracted azuliporphyrins, and related conjugated compounds.
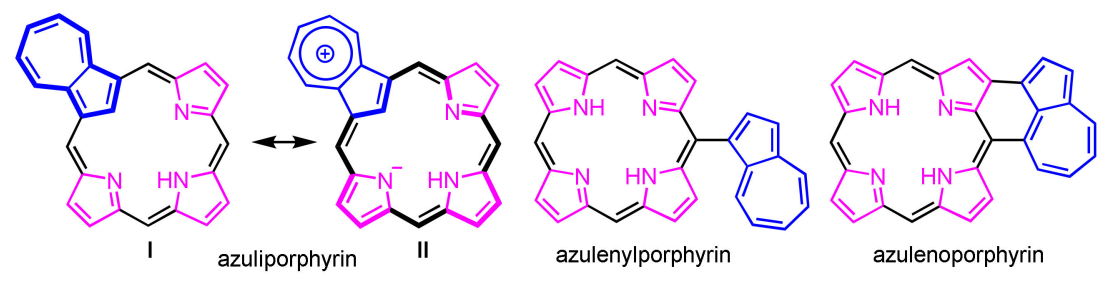

Figure 1. Structures of porphyrinoids incorporated with azulene.

Azulene (1) favors the electrophilic substitution reaction at the 1,3-positions, which structurally resemble pyrrole at the $\alpha$-positions. Thus, azulene (1) is used as an ideal precursor for the construction of carbaporphyrinoid. The azuliporphyrin skeleton is constructed via the following routes: (a) [3 + 1] MacDonald condensation [80], (b) back-to-front [3 + 1] strategy [87], (c) [2 + 2] MacDonald condensation [88] and (d) Lindsey-Rothemund-type condensation [89] (Scheme 58). 


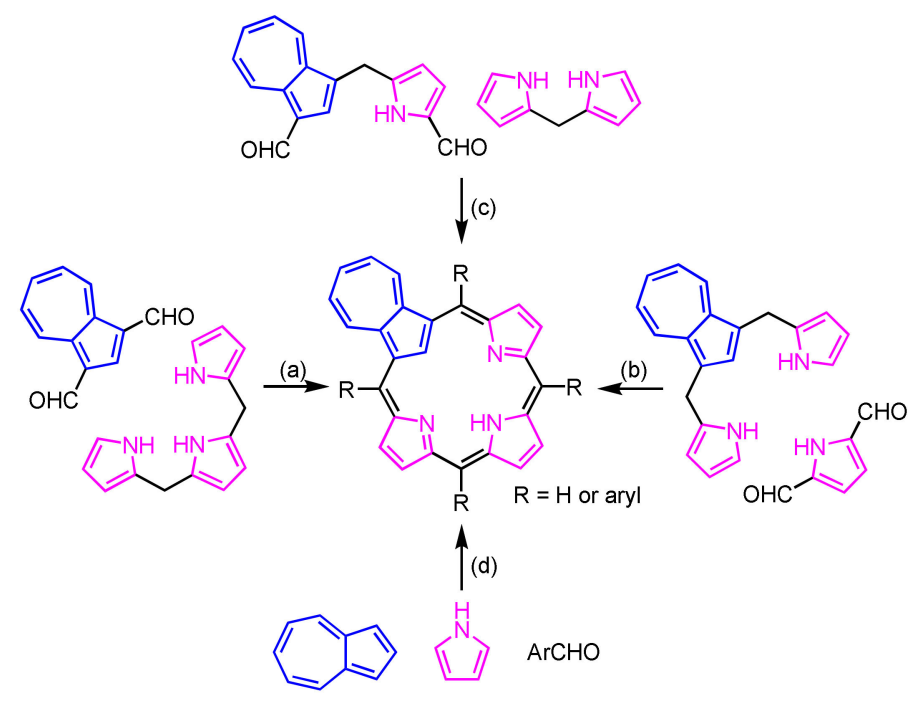

Scheme 58. Construction of azuliporphyrin frameworks.

Back-to-front $[3+1]$ synthesis afforded various azuliporphyrin derivatives by taking advantage of stable azulitripyrrane. This method was adopted for the preparation of mono-, di-, and tribenzoazuliporphyrins [90]. Bicyclo[2.2.2]octadiene-fused azuliporphyrin $\mathbf{1 7 6}$ was prepared by condensation of azulitripyrrane 174 with 2,5-diformylpyrrole 175, followed by oxidation with $\mathrm{FeCl}_{3}$ before tribenzoazuliporphyrin 177 was quantitatively obtained via retro Diels-Alder reaction (Scheme 59).

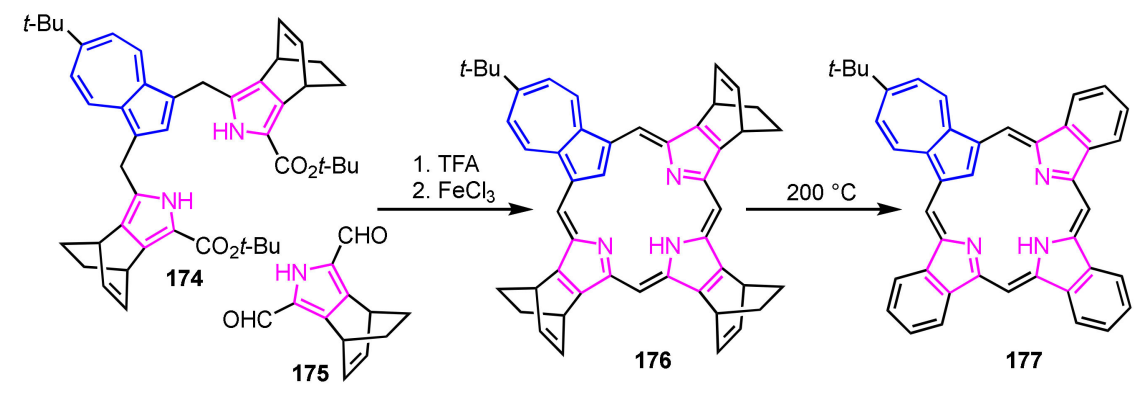

Scheme 59. Synthesis of tribenzoazuliporphyrin 177 via retro Diels-Alder reaction.

Lash and co-workers reported azulichlorins via [2 +2] condensation. Azulidipyrrane 178 and dihydrodipyrrin 179 were treated with TFA to remove the tert-butyl ester groups. After dilution with acetic acid and addition of $\mathrm{HI}$, the reaction mixture was stirred at room temperature overnight. The protonated azulichlorin 180 was obtained, resulting from the cross-condensation in $17 \%$ yield (Scheme 60) [91]. In this reaction, the self-condensation products were not obtained. The NMR spectrum of 180 shows the internal $\mathrm{CH}$ at $-2.11 \mathrm{ppm}$ and meso-CHs at 7.5-9.3 ppm, which indicates that the cation $\mathbf{1 8 0}$ has a similar diamagnetic ring current to protonated azuliporphyrins due to the contribution of resonance structure of the $18 \pi$-electron system as shown in Scheme 60. 


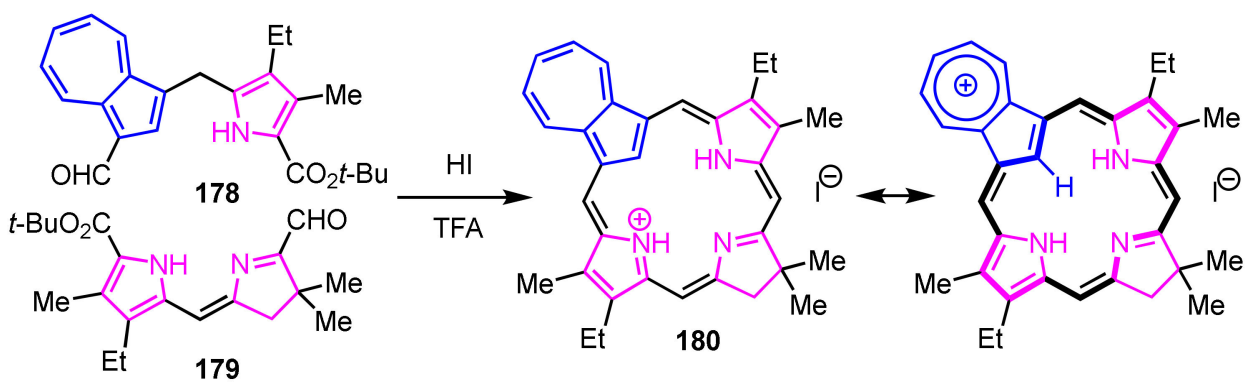

Scheme 60. Synthesis of protonated azulichlorin $\mathbf{1 8 0}$

There are few ring-expanded/contracted azuliporphyrinoids while a variety of azuliporphyrins were reported (Figure 2). Lash and co-workers reported a [4+1] route to azulisapphyrin with a $22 \pi$-system [92]. Diazulihexaphyrin(3.3.1.3.3.1) was reported under [2 +1$]$ condensation between a dipyrromethane and an azulene bisacrylaldehyde, which did not show macrocyclic aromaticity [93]. Latos-Grażyński and co-workers reported dithiaethyneazuliporphyrin with a nonaromatic triphyrin(4.1.1) framework [94].

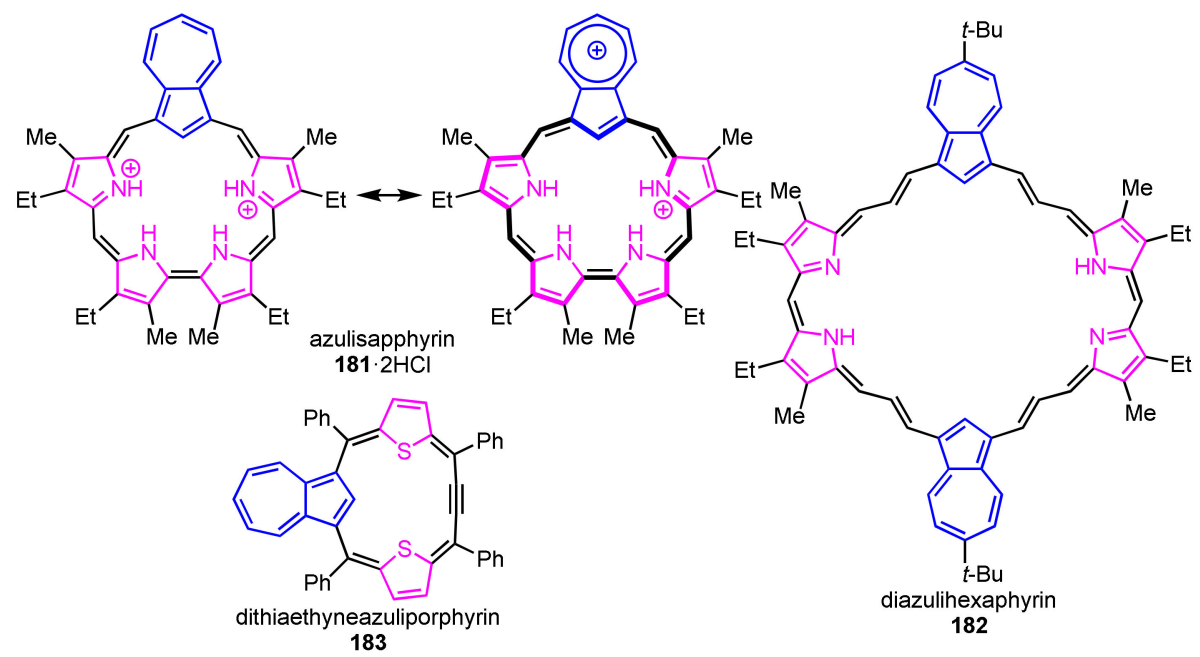

Figure 2. Reported ring-expanded/contracted azuliporphyrins 181-183.

Ghosh and co-workers reported azulicorrole as the first carbacorrole except for $\mathrm{N}$-confused corroles in 2019 [95,96]. Azulicorrole 184 was isolated via acid-catalyzed condensation of azulene, pyrrole and $p$-trifluoromethylbenzaldehyde with a molar ratio of 1.5:4.5:2.5, followed by oxidation with DDQ (Scheme 61). Although the yield was poor, free base $\mathbf{1 8 4}$ was readily converted into the $\mathrm{Cu}(\mathrm{III})$ and $\mathrm{Au}(\mathrm{III})$ complexes. The NMR spectrum of $\mathbf{1 8 4}$ shows signals of the internal $\mathrm{CH}$ at $3.19 \mathrm{ppm}$ and NHs at 3.47 ppm, indicating that $\mathbf{1 8 4}$ has a lower diatropic ring current compared to triarylcorroles.

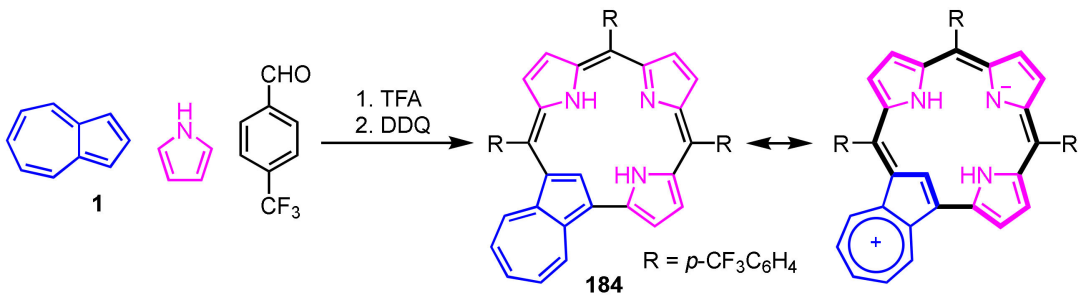

Scheme 61. Synthesis of azulicorrole 184.

Okujima et al. [97] and Lash et al. [98] subsequently reported azulitriphyrin with triphyrin(2.1.1) framework. Intramolecular McMurry coupling of diformyltripyrrane is a key step for the construction 
of the triphyrin(2.1.1) framework (Scheme 62) [99]. Tetrahydroazulitriphyrin was obtained via McMurry coupling of 185. Oxidation with DDQ and treatment with TFA afforded protonated azulitriphyrin 188 as a trifluoroacetate. The NMR spectrum of $\mathbf{1 8 2}$ shows signals of the internal $\mathrm{CH}$ at $2.53 \mathrm{ppm}$ and NHs at $10.86 \mathrm{ppm}$, which are upfield-shifted compared to those of $\mathbf{1 8 7}$ due to global diatropic ring current. The NICS calculations also supported that azulitriphyrin 188 is a $14 \pi$-electron aromatic system.
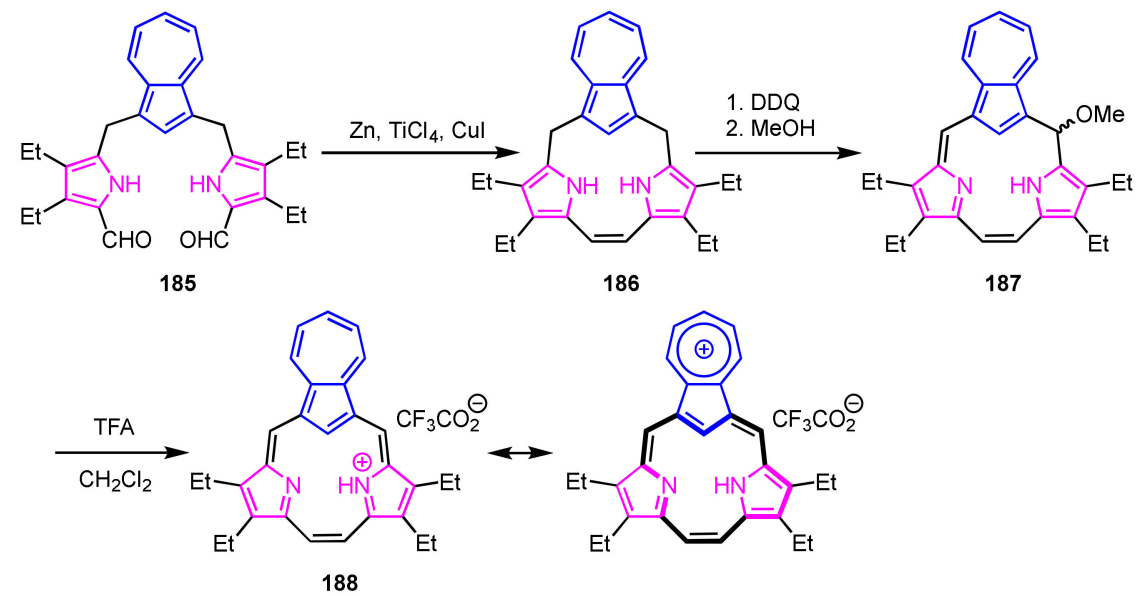

Scheme 62. Synthesis of azulitriphyrin 188 with triphyrin(2.1.1) framework.

In 2019, Takase, Uno, and co-workers reported azulene-fused azacoronene analogue 190 (Scheme 63) [100]. Suzuki-Miyaura cross-coupling reaction of bromopentafluorobenzene with the corresponding azulenylboronate, followed by the nucleophilic aromatic substitution with 3,4-diethylpyrrole, gave 2-azulenylpentapyrrolylbenzene 189. Azulene-fused azacoronene 190 was obtained via the Scholl reaction with $\mathrm{FeCl}_{3}$ in a moderate yield. This azacoronene showed reversible multistep-oxidations similar to hexapyrrolohexaazacorone [101]. Dication 191 was isolated via oxidation of $\mathbf{1 9 0}$ with $\mathrm{AgPF}_{6}$ or $\mathrm{SbCl}_{5}$ and showed a $22 \pi$-electron conjugation with azulihexaphyrin(0.0.0.0.0.0) framework confirmed by the crystal analysis and the NICS and ACID calculations.

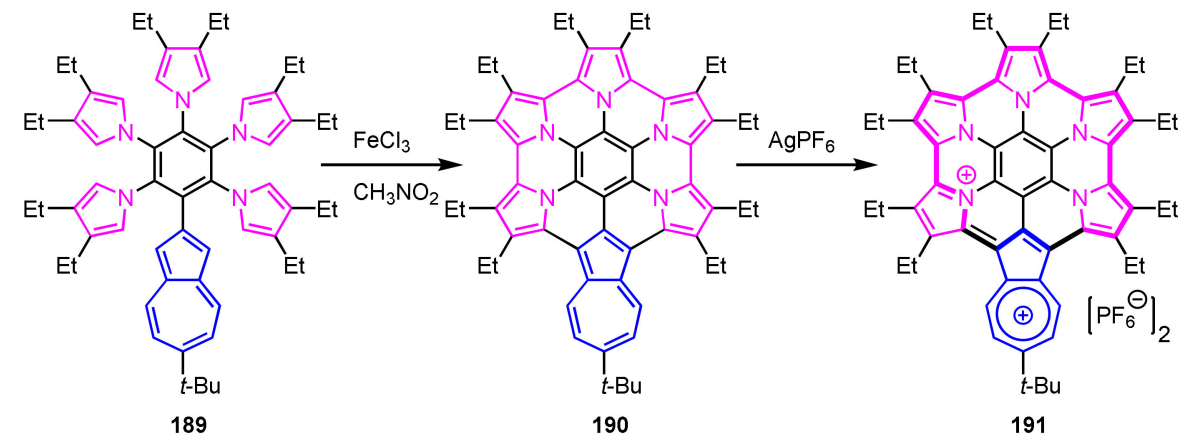

Scheme 63. Synthesis of azulene-fused azacoronene analogue 190.

\section{Conclusions}

In this review, we summarize the preparation, reactivity, and physical properties of heterocycle-substituted and heterocycle-fused azulene derivatives that have been reported in the last decade. There are a wide variety of methods for their synthetic approach and the physical properties of the azulene derivatives are highly dependent on the type of heterocycles and their substitution and fused positions.

1-Heteroaryl- and 1,3-bis(heteroaryl)azulene derivatives have been prepared by various methods, including electrophilic substitution, cyclization, radical coupling, and transition metal-catalyzed 
cross-coupling reactions, whereas the introduction of a heterocycle to the 2- and 6-positions of azulene ring is mostly achieved by cross-coupling reactions using the corresponding haloazulenes as a starting material because of the low reactivity of electrophiles to these sites. There is only one example of electrophilic substitution reaction by heterocyclic compound at the 2-position of the azulene ring, but in this case, a strong electron-donating group such as a dimethylamino group at the 6-position and protection at the 1,3-positions of the azulene ring are both essential. Recently, the reaction of $2 \mathrm{H}$-cyclohepta[b]furan-2-one derivatives 192 with heterocycle-substituted silyl enol ethers have been reported as a new synthetic method for 2-heteroarylazulenes without using cross-coupling reactions (Scheme 64) [102]. This method is applied to the synthesis of azulenes with various heterocycles such as 2-(pyridyl-, thienyl-, furyl-, and pyrrolyl)azulenes 193, although the reaction requires high temperature $\left(190{ }^{\circ} \mathrm{C}\right)$. Furthermore, the ester group of 194 can be removed by decarboxylation with $100 \% \mathrm{H}_{3} \mathrm{PO}_{4}$.

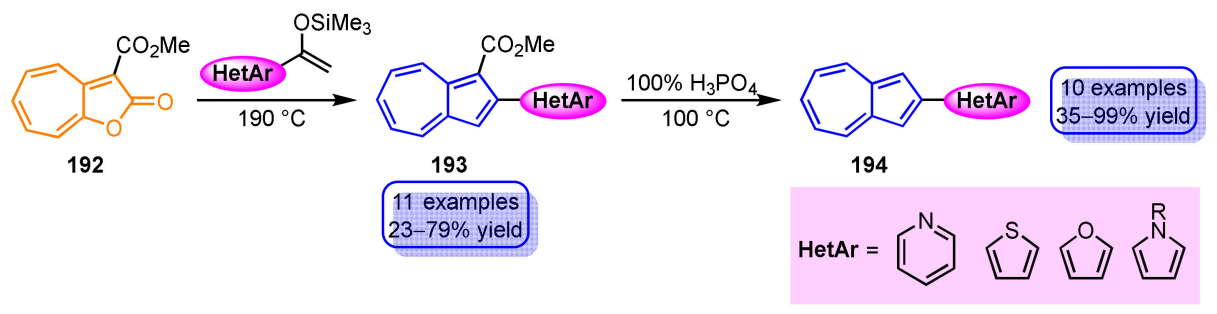

Scheme 64. Synthesis of 2-heteroarylazulenes 190.

The synthesis of azulene derivatives with heterocyclic substitutions at the 4-, 5-, and 6-positions can be accomplished by a variety of methods, such as Zieglar-Hafner method, aromatic nucleophilic substitution, and cross-coupling reactions.

The synthetic methods described in this review are extremely beneficial for the preparation of novel heterocycle-substituted and heterocycle-fused azulene derivatives that have growth potential as organic electronics and pharmaceuticals.

Author Contributions: All authors wrote and reviewed the manuscript. Conceptualization, T.S., T.O. and S.I.; Writing-Original Draft Preparation, T.S., T.O. and S.I.; Writing-Review \& Editing, T.S., T.O. and S.I. All authors have read and agreed to the published version of the manuscript.

Funding: This research received no external funding.

Conflicts of Interest: The authors declare no conflict of interest.

\section{References}

1. Yanagisawa, T.; Wakabayashi, S.; Tomiyama, T.; Yasunami, M.; Takase, K. Synthesis and Anti-ulcer Activities of Sodium Alkylazulene Sulfonates. Chem. Pharm. Bull. 1988, 36, 641-647. [CrossRef] [PubMed]

2. Yanagisawa, T.; Kosakai, K.; Tomiyama, T.; Yasunami, M.; Takase, K. Studies on Anti-ulcer Agents. II. Synthesis and Anti-ulcer Activities of 6-Isopropylazulene-1-sodium Sulfonate Derivatives. Chem. Pharm. Bull. 1990, 38, 3355-3358. [CrossRef] [PubMed]

3. Yanagisawa, T.; Kosakai, K.; Izawa, C.; Tomiyama, T.; Yasunami, M. Synthesis and Anti-peptic Activity of Compounds Related to the Metabolites of Sodium 3-Ethyl-7-isopropyl-1-azulenesulfonate (KT1-32). Chem. Pharm. Bull. 1991, 39, 2429-2432. [CrossRef] [PubMed]

4. Wada, T.; Maruyama, R.; Irie, Y.; Hashimoto, M.; Wakabayashi, H.; Okudaira, N.; Uesawa, Y.; Kagaya, H.; Sakagami, H. In Vitro Anti-tumor Activity of Azulene Amide Derivatives. In Vivo 2018, 32, 479-486. [PubMed]

5. Uehara, M.; Minemura, H.; Ohno, T.; Hashimoto, M.; Wakabayashi, H.; Okudaira, N.; Sakagami, H. In Vitro Antitumor Activity of Alkylaminoguaiazulenes. In Vivo 2018, 32, 541-547. [PubMed]

6. Imanari, K.; Hashimoto, M.; Wakabayashi, H.; Okudaira, N.; Bandow, K.; Nagai, J.; Tomomura, M.; Tomomura, A.; Uesawa, Y.; Sakagami, H. Quantitative Structure-Cytotoxicity Relationship of Azulene Amide Derivatives. Anticancer Res. 2019, 39, 3507-3518. [CrossRef] 
7. Ayaz, F.; Yuzer, A.; Ince, T.; Ince, M. Anti-Cancer and Anti-Inflammatory Activities of Bromo- and Cyano-Substituted Azulene Derivatives. Inflammation 2020, 43, 1009-1018. [CrossRef]

8. Fischer, G. Azulenes Fused to Heterocycles. Adv. Heterocyclic Chem. 2009, 97, 131-218.

9. Abe, N.; Gunji, T. The Chemistry of Azaazulenes. Heterocycles 2010, 82, 201-248. [CrossRef]

10. Ito, S.; Shoji, T.; Morita, N. Recent Advances in the Development of Methods for the Preparation of Functionalized Azulenes for Electrochromic Applications. Synlett 2011, 16, 2279-2298. [CrossRef]

11. Dong, J.-X.; Zhang, H.-L. Azulene-based organic functional molecules for optoelectronics. Chin. Chem. Lett. 2016, 27, 1097-1104. [CrossRef]

12. Shoji, T.; Ito, S. Azulene-Based Donor-Acceptor Systems: Synthesis, Optical, and Electrochemical Properties. Chem. Eur. J. 2017, 23, 16696-16709. [CrossRef] [PubMed]

13. Xin, H.; Gao, X. Application of Azulene in Constructing Organic Optoelectronic Materials: New Tricks for an Old Dog. ChemPlusChem 2017, 82, 945-956. [CrossRef] [PubMed]

14. Shoji, T.; Ito, S. The Preparation and Properties of Heteroarylazulenes and Hetero-Fused Azulenes. Adv. Heterocyclic Chem. 2018, 126, 1-54.

15. Abe, N. Recent Advances in the Chemistry of Azaazulenes and Related Compounds. Heterocycles 2018, 101, 33-89. [CrossRef]

16. Razus, A.C.; Birzan, L. Synthesis of azulenic compounds substituted in the 1-position with heterocycles. Monatsh. Chem. 2019, 150, 139-161. [CrossRef]

17. Ou, L.; Zhou, Y.; Wu, B.; Zhu, L. The unusual physicochemical properties of azulene and azulene-based compounds. Chin. Chem. Lett. 2019, 30, 1903-1907. [CrossRef]

18. Wu, C.-P.; Devulapally, R.; Li, T.-C.; Ku, C.-K.; Chung, H.-C. Efficient syntheses of $3 \mathrm{H}$-azuleno[8,1-cd]pyridazines and their thermal and photochemical reactions. Tetrahedron Lett. 2010, 51,4819-4822. [CrossRef]

19. Wang, D.-L.; Li, Y.-F.; Xu, J.; Li, W.; Li, S.-F.; Lin, L.-N. A Facile Synthesis of 2-Substituted 2,3-Dihydro-4(1H)-azuleno[1,2-d]pyrimidinones. Heterocycles 2011, 83, 365-370. [CrossRef]

20. Kiriazis, A.; Aumuller, I.B.; Yli-Kauhaluoma, J. Synthesis of 4-aminoguaiazulene and its $\delta$-lactam derivatives. Tetrahedron Lett. 2011, 52, 1151-1153. [CrossRef]

21. Wakabayashi, S.; Yamaoka, R.; Matsumoto, E.; Nishiguchi, M.; Ishiura, M.; Tsuji, M.; Shimizu, M. Sulfur-Containing Pyridylazulenes: Synthesis and Chromogenic Behaviors for Heavy Metal Ions. Heterocycles 2012, 85, 2251-2258. [CrossRef]

22. Wang, D.-L.; Dong, Z.; Cui, Q.-T.; Yang, F.-F.; Zhao, W. Synthesis of Some Pyrazole-Fused Pyrido[3,2-a]azulenes. Heterocycles 2013, 87, 2343-2350. [CrossRef]

23. Wang, D.-L.; Ma, J.; Shi, X.-C.; Wu, J.-Y. An Efficient One-Pot Synthesis of Azuleno[2,1-b]pyridazines. Heterocycles 2016, 92, 133-140. [CrossRef]

24. Shoji, T.; Okada, K.; Ito, S.; Toyota, K.; Morita, N. Synthesis of 1-(pyridyl, quinolyl, and isoquinolyl)azulenes by Reissert-Henze type reaction. Tetrahedron Lett. 2010, 51, 5127-5130. [CrossRef]

25. Shoji, T.; Inoue, Y.; Ito, S.; Okujima, T.; Morita, N. First Synthesis of 2-Heteroarylazulenes by the Electrophilic Substitution of Azulene with Triflate of N-Containing Heterocycles. Heterocycles 2012, 85, 35-41. [CrossRef]

26. Shoji, T.; Maruyama, A.; Ito, S.; Okujima, T.; Yasunami, M.; Higashi, J.; Morita, N. Synthesis of 2-Aryl- and 6-Heteroaryl-1,3-di(4-pyridyl)azulenes by Katritzky's Pyridylation of 2-Aryl- and 6-Heteroarylazulenes. Heterocycles 2014, 89, 2588-2603. [CrossRef]

27. Dubovik, J.; Bredihhin, A. A Convenient Synthesis of Functionalized Azulenes via Negishi Cross-Coupling. Synthesis 2015, 47, 538-548.

28. Dubovik, J.; Bredihhin, A. The First Preparation of Azulenylzinc Reagents and Their Use in Negishi Cross-Coupling. Synthesis 2015, 47, 2663-2669.

29. Cowper, P.; Jin, Y.; Turton, M.D.; Kociok-Koehn, G.; Lewis, S.E. Azulenesulfonium Salts: Accessible, Stable, and Versatile Reagents for Cross-Coupling. Angew. Chem. Int. Ed. 2016, 55, 2564-2568. [CrossRef]

30. Ion, A.E.; Cristian, L.; Voicescu, M.; Bangesh, M.; Madalan, A.M.; Bala, D.; Mihailciuc, C.; Nica, S. Synthesis and properties of fluorescent $4^{\prime}$-azulenyl-functionalized 2,2':6',2"-terpyridines. Beilstein J. Org. Chem. 2016, 12, 1812-1825. [CrossRef]

31. Xin, H.; Li, J.; Yang, X.; Gao, X. Azulene-Based BN-Heteroaromatics. J. Org. Chem. 2020, 85, 70-78. [CrossRef] [PubMed] 
32. Wang, D.-L.; Feng, S.-S.; Cui, Q.-T.; Yu, J.-Y. An Efficient One-Pot Synthesis of 1-Amino-3-cyano-4-aryl-10-ethoxycarbonylazuleno[2,1-b]pyrans. Heterocycles 2012, 85, 441-448. [CrossRef]

33. Sato, K.; Yokoo, E.; Takenaga, N. An Efficient One-Pot Synthesis of 1-Amino-3-cyano-4-aryl-10-ethoxycarbonylazuleno[2,1-b]pyrans. Heterocycles 2013, 87, 807-814. [CrossRef]

34. Ito, S.; Yamazaki, S.; Kudo, S.; Sekiguchi, R.; Kawakami, J.; Takahashi, M.; Matsuhashi, T.; Toyota, K.; Morita, N. Synthesis and redox behavior of 1,2-dihydro-1-oxabenz[a]azulen-2-ones. Tetrahedron 2014, 70, 2796-2803. [CrossRef]

35. Shoji, T.; Tanaka, M.; Takagaki, S.; Miura, K.; Ohta, A.; Sekiguchi, R.; Ito, S.; Mori, S.; Okujima, T. Synthesis of azulene-substituted benzofurans and isocoumarins via intramolecular cyclization of 1-ethynylazulenes, and their structural and optical properties. Org. Biomol. Chem. 2018, 16, 480-489. [CrossRef] [PubMed]

36. Shoji, T.; Tanaka, M.; Araki, T.; Takagaki, S.; Sekiguchi, R.; Ito, S. Synthesis of 1-azulenyl ketones by Brønsted acid mediated hydration of 1-azulenylalkynes. RSC Adv. 2016, 6, 78303-78306. [CrossRef]

37. Okujima, T.; Toda, A.; Miyashita, Y.; Nonoshita, A.; Yamada, H.; Ono, N.; Uno, H. Synthesis and Properties of Azulene-Substituted Thiophenes, Terthiophenes and Dithienothiophenes. Heterocycles 2012, 86, 637-648. [CrossRef]

38. Sato, O.; Sakai, A.; Aoki, M.; Kuramochi, T.; Nakayama, J. Azulenopentathiepin: Preparation and Conversion into Azulenes with Sulfur Groups at The 1- and 2-Positions. Heterocycles 2012, 86, 1253-1260. [CrossRef]

39. Sato, O.; Saito, T.; Aoki, M.; Sakai, A. Azulene-Based Tetrathiafulvalenes: Preparation and Their Electron-Donating Ability. Heterocycles 2017, 95, 1254-1260. [CrossRef]

40. Shoji, T.; Ito, S.; Okujima, T.; Morita, N. Synthesis of push-pull chromophores by the sequential [2+2] cycloaddition of 1-azulenylbutadiynes with tetracyanoethylene and tetrathiafulvalene. Org. Biomol. Chem. 2012, 10, 8308-8313. [CrossRef]

41. Shoji, T.; Araki, T.; Sugiyama, S.; Ohta, A.; Sekiguchi, R.; Ito, S.; Okujima, T.; Toyota, K. Synthesis of 2-Azulenyltetrathiafulvalenes by Palladium-Catalyzed Direct Arylation of 2-Chloroazulenes with Tetrathiafulvalene and Their Optical and Electrochemical Properties. J. Org. Chem. 2017, 82, 1657-1665. [CrossRef]

42. Shoji, T.; Shimomura, E.; Inoue, Y.; Maruyama, M.; Yamamoto, A.; Fujimori, K.; Ito, S.; Yasunami, M.; Morita, N. Synthesis of Novel Thiophene-Fused 1,1'-Biazulene Derivative by the Reaction of Azuleno[1,2-b]thiophene with N-Iodosuccinimide. Heterocycles 2013, 87, 303-306. [CrossRef]

43. Shoji, T.; Miura, K.; Ariga, Y.; Yamazaki, A.; Ito, S.; Yasunami, M. Synthesis of Thiophene-fused Heptalenes by Cycloaddition of Azulenothiophenes with Dimethyl Acetylenedicarboxylate. Sci. Rep. 2020, 1012477.

44. Kitai, J.-I.; Kobayashi, T.; Uchida, W.; Hatakeyama, M.; Yokojima, S.; Nakamura, S.; Uchida, K. Photochromism of a Diarylethene Having an Azulene Ring. J. Org. Chem. 2012, 77, 3270-3276. [CrossRef] [PubMed]

45. Yamaguchi, Y.; Maruya, Y.; Katagiri, H.; Nakayama, K.-I.; Ohba, Y. Synthesis, Properties, and OFET Characteristics of 5,5'-Di(2-azulenyl)-2,2'-bithiophene (DAzBT) and 2,5-Di(2-azulenyl)-thieno[3,2-b]thiophene (DAzTT). Org. Lett. 2012, 14, 2316-2319. [CrossRef] [PubMed]

46. Wang, F.; Lin, T.T.; He, C.; Chi, H.; Tanga, T.; Lai, Y.-H. Azulene-containing organic chromophores with tunable near-IR absorption in the range of 0.6 to $1.7 \mu \mathrm{m}$. J. Mater. Chem. 2012, 22, 10448-10451. [CrossRef]

47. Shoji, T.; Maruyama, A.; Araki, T.; Ito, S.; Okujima, T. Synthesis of 2- and 6-thienylazulenes by palladium-catalyzed direct arylation of 2- and 6-haloazulenes with thiophene derivatives. Org. Biomol. Chem. 2015, 13, 10191-10197. [CrossRef] [PubMed]

48. Dragu, E.A.; Ion, A.E.; Shova, S.; Bala, D.; Mihailciuc, C.; Voicescu, M.; Ionescu, S.; Nica, S. Visible-light triggered photoswitching systems based on fluorescent azulenyl-substituted dithienylcyclopentenes. RSC Adv. 2015, 5, 63282-63286. [CrossRef]

49. Amir, E.; Amir, R.J.; Campos, L.M.; Hawker, C.J. Stimuli-Responsive Azulene-Based Conjugated Oligomers with Polyaniline-like Properties. J. Am. Chem. Soc. 2011, 133, 10046-10049. [CrossRef]

50. Amir, E.; Murai, M.; Amir, R.J.; Cowart, J.S., Jr.; Chabinyc, M.L.; Hawker, C.J. Conjugated oligomers incorporating azulene building blocks - seven- vs. five-membered ring connectivity. Chem. Sci. 2014, 5, 4483-4489. [CrossRef] 
51. Cowper, P.; Pockett, A.; Kociok-Köhn, G.; Cameron, P.J.; Lewis, S.E. Azulene - Thiophene - Cyanoacrylic acid dyes with donor- $\pi$-acceptor structures. Synthesis, characterisation and evaluation in dye-sensitized solar cells. Tetrahedron 2018, 74, 2775-2786. [CrossRef]

52. Shoji, T.; Miura, K.; Ohta, A.; Sekiguchi, R.; Ito, S.; Endo, Y.; Nagahata, T.; Mori, S.; Okujima, T. Synthesis of azuleno[2,1-b]thiophenes by cycloaddition of azulenylalkynes with elemental sulfur and their structural, optical and electrochemical properties. Org. Chem. Front. 2019, 6, 2801-2811. [CrossRef]

53. Hyoudou, M.; Nakagawa, H.; Gunji, T.; Ito, Y.; Kawai, Y.; Ikeda, R.; Konakahara, T.; Abe, N. Synthesis, Cyclization, and Evaluation of the Anticancer Activity against HeLa S-3 Cells of Ethyl 2-Acetylamino-3-ethynylazulene-1-carboxylates. Heterocycles 2012, 86, 233-244. [CrossRef]

54. Tsukada, S.; Nakazawa, M.; Okada, Y.; Ohtsu, K.; Abe, N.; Gunji, T. Synthesis of 2-Arylamino-1-azaazulenes. Heterocycles 2017, 95, 624-635. [CrossRef]

55. Shoji, T.; Inoue, Y.; Ito, S. First synthesis of 1-(indol-2-yl)azulenes by the Vilsmeier-Haack type arylation with triflic anhydride as an activating reagent. Tetrahedron Lett. 2012, 53, 1493-1496. [CrossRef]

56. Shoji, T.; Takagaki, S.; Tanaka, M.; Araki, T.; Sugiyama, S.; Sekiguchi, R.; Ohta, A.; Ito, S.; Okujima, T. Synthesis of Azulene-Substituted Tetraarylpyrroles by Reaction of 1-Azulenyl Ketones with Benzoin and Ammonium Acetate. Heterocycles 2017, 94, 1870-1883. [CrossRef]

57. Poronik, Y.M.; Mazur, L.M.; Samoć, M.; Jacquemin, D.; $\quad$ Gryko, D.T. 2,5-Bis(azulenyl)pyrrolo[3,2-b]pyrroles-the key influence of the linkage position on the linear and nonlinear optical properties. J. Mater. Chem. C 2017, 5, 2620-2628. [CrossRef]

58. Zhang, L.; Wang, D.-L.; Xing, J.-J.; Liu, L. One-Pot Synthesis of 3-(Guaiazulen-3-yl)dihydro-1Hindol-4(5H)-ones via Domino Reaction. Heterocycles 2019, 98, 1547-1554.

59. Zhang, L.; Wang, D.-L.; Xing, J.-J.; Liu, L. Facile Synthesis of (Guaiazulen-1-yl)-1H-pyrroles via Paal-Knorr Reaction. Heterocycles 2019, 98, 1555-1562.

60. Kogawa, C.; Fujiwara, A.; Sekiguchi, R.; Shoji, T.; Kawakami, J.; Okazaki, M.; Ito, S. Synthesis and photophysical properties of azuleno[1',2':4,5]pyrrolo[2,1-b]quinazoline-6,14-diones: Azulene analogs of tryptanthrin. Tetrahedron 2018, 74, 7018-7029. [CrossRef]

61. Wu, C.-P.; Devendar, B.; Su, H.-C.; Chang, Y.-H.; Ku, C.-K. Efficient synthesis and applications of 2-substituted azulene derivatives: Towards highly functionalized carbo- and heterocyclic molecules. Tetrahedron Lett. 2012, 53, 5019-5022. [CrossRef]

62. Wang, D.-L.; Dong, Z.; Xu, J.; Li, D. An efficient synthesis of 2-(guaiazulen-1-yl)furan derivatives via intramolecular Wittig reactions. Chin. Chem. Lett. 2013, 24, 622-624. [CrossRef]

63. Murai, M.; Ku, S.-Y.; Treat, N.D.; Robb, M.J.; Chabinyc, M.L.; Hawker, C.J. Modulating structure and properties in organic chromophores: Influence of azulene as a building block. Chem. Sci. 2014, 5, 3753-3760. [CrossRef]

64. Shoji, T.; Nagai, D.; Tanaka, M.; Araki, T.; Ohta, A.; Sekiguchi, R.; Ito, S.; Mori, S.; Okujima, T. Synthesis of 2-Aminofurans by Sequential [2+2] Cycloaddition-Nucleophilic Addition of 2-Propyn-1-ols with Tetracyanoethylene and Amine-Induced Transformation into 6-Aminopentafulvenes. Chem. Eur. J. 2017, 23, 5126-5136. [CrossRef] [PubMed]

65. Shoji, T.; Iida, N.; Yamazaki, A.; Ariga, Y.; Ohta, A.; Sekiguchi, R.; Nagahata, T.; Nagasawa, T.; Ito, S. Synthesis of phthalimides cross-conjugated with an azulene ring, and their structural, optical and electrochemical properties. Org. Biomol. Chem. 2020, 18, 2274-2282. [CrossRef] [PubMed]

66. Matano, Y.; Kon, Y.; Saito, A.; Kimura, Y.; Murafuji, T.; Imahori, H. Divergent Synthesis of 2,5-Diarylphospholes Based on Cross-coupling Reactions: Substituent Effects on the Optical and Redox Properties of Benzene-Phosphole-Benzene $\pi$-Systems. Chem. Lett. 2011, 40, 919-921. [CrossRef]

67. Shoji, T.; Fujiwara, Y.; Maruyama, A.; Maruyama, M.; Ito, S.; Yasunami, M.; Yokoyama, R.; Morita, N. Synthesis of 2,6-Diaminoazulenes by the SNAr Reaction with Cyclic Amines. Heterocycles 2015, 90, 85-88. [CrossRef]

68. Shoji, T.; Sugiyama, S.; Takeuchi, M.; Ohta, A.; Sekiguchi, R.; Ito, S.; Yatsu, T.; Okujima, T.; Yasunami, M. Synthesis of 6-Amino- and 6-Arylazoazulenes via Nucleophilic Aromatic Substitution and Their Reactivity and Properties. J. Org. Chem. 2019, 84, 1257-1275. [CrossRef]

69. Wakabayashi, S.; Uchida, M.; Tanaka, R.; Habata, Y.; Shimizu, M. Synthesis of Azulene Derivatives That Have an Azathiacrown Ether Moiety and Their Selective Color Reaction Towards Silver Ions. Asian J. Org. Chem. 2013, 2, 786-791. [CrossRef] 
70. Nishimura, H.; Ishida, N.; Shimazaki, A.; Wakamiya, A.; Saeki, A.; Scott, L.T.; Murata, Y. Hole-Transporting Materials with a Two-Dimensionally Expanded $\pi$-System around an Azulene Core for Efficient Perovskite Solar Cells. J. Am. Chem. Soc. 2015, 137, 15656-15659. [CrossRef]

71. Nishimura, H.; Eliseeva, M.N.; Wakamiya, A.; Scott, L.T. 3,5,7-Tetra(Bpin)azulene by Exhaustive Direct Borylation of Azulene and 5,7-Di(Bpin)azulene by Selective Subsequent Deborylation. Synlett 2015, 26, 1578-1580.

72. Murafuji, T.; Shintaku, K.; Nagao, K.; Mikata, Y.; Ishiguro, K.; Kamijo, S. Synthesis and Structural Characterization of Diazulenylborinic Acid. Heterocycles 2017, 94, 676-690. [CrossRef]

73. Murfin, L.C.; Weber, M.; Park, S.-J.; Kim, W.-T.; Lopez-Alled, C.M.; McMullin, C.L.; Pradaux-Caggiano, F.; Lyall, C.L.; Kociok-Kohn, G.; Wenk, J.; et al. Azulene-Derived Fluorescent Probe for Bioimaging: Detection of Reactive Oxygen and Nitrogen Species by Two-Photon Microscopy. J. Am. Chem. Soc. 2019, 141, 19389-19396. [CrossRef] [PubMed]

74. Murfin, L.C.; Chiang, K.; Williams, G.T.; Lyall, C.L.; Jenkins, A.T.A.; Wenk, J.; James, T.D.; Lewis, S.E. A Colorimetric Chemosensor Based on a Nozoe Azulene That Detects Fluoride in Aqueous/Alcoholic Media. Front. Chem. 2020. [CrossRef] [PubMed]

75. Xin, H.; Ge, C.; Yang, X.; Gao, H.; Yang, X.; Gao, X. Biazulene diimides: A new building block for organic electronic materials. Chem. Sci. 2016, 7, 6701-6705. [CrossRef]

76. Xin, H.; Ge, C.; Jiao, X.; Yang, X.; Rundel, K.; McNeill, C.R.; Gao, X. Incorporation of 2,6-Connected Azulene Units into the Backbone of Conjugated Polymers: Towards High-Performance Organic Optoelectronic Materials. Angew. Chem. Int. Ed. 2018, 57, 1322-1326. [CrossRef]

77. Koide, T.; Takesue, M.; Murafuji, T.; Satomi, K.; Suzuki, Y.; Kawamata, J.; Terai, K.; Suzuki, M.; Yamada, H.; Shiota, Y.; et al. An Azulene-Fused Tetracene Diimide with a Small HOMO-LUMO Gap. ChemPlusChem 2017, 82, 1010-1014. [CrossRef]

78. Shoji, T.; Araki, T.; Iida, N.; Miura, K.; Ohta, A.; Sekiguchi, R.; Ito, S.; Okujima, T. Synthesis of azulenophthalimides by phosphine-mediated annulation of 1,2-diformylazulenes with maleimides. Org. Chem. Front. 2019, 6, 195-204. [CrossRef]

79. Lash, T.D.; Chaney, S.T. Azuliporphyrin: A Case of Borderline Porphyrinoid Aromaticity. Angew. Chem. Int. Ed. Engl. 1997, 36, 839-840. [CrossRef]

80. Kurotobi, K.; Osuka, A. Synthesis of meso-Azulenylporphyrins. Org. Lett. 2005, 7, 1055-1058. [CrossRef]

81. Kurotobi, K.; Kim, K.S.; Noh, S.B.; Kim, D.; Osuka, A. A Quadruply Azulene-Fused Porphyrin with Intense Near-IR Absorption and a Large Two-Photon Absorption Cross Section. Angew. Chem. Int. Ed. 2006, 45, 3944-3947. [CrossRef] [PubMed]

82. Lash, T.D. The Porphyrin Handbook; Kadish, K.M., Smith, K.M., Guilard, R., Eds.; Academic Press: San Diego, CA, USA, 2000; Volume 2, pp. 165-193.

83. Pawlicki, M.; Latos-Grażyński, L. Handbook of Porphyrin Science; Kadish, K.M., Smith, K.M., Guilard, R., Eds.; World Scientific: Singapore, 2010; Volume 2, pp. 103-192.

84. Lash, T.D. Handbook of Porphyrin Science; Kadish, K.M., Smith, K.M., Guilard, R., Eds.; World Scientific: Singapore, 2012; Volume 16, pp. 1-329.

85. Lash, T.D. Out of the Blue! Azuliporphyrins and Related Carbaporphyrinoid Systems. ACC Chem. Res. 2016, 49, 471-482. [CrossRef] [PubMed]

86. Lash, T.D. Carbaporphyrinoid Systems. Chem. Rev. 2017, 117, 2313-2446. [CrossRef]

87. Graham, S.R.; Colby, D.A.; Lash, T.D. An Azulene Analogue of the Tripyrranes and Carbaporphyrinoids Therefrom. Angew. Chem. Int. Ed. 2002, 41, 1371-1374. [CrossRef]

88. Lash, T.D.; Lammer, A.D.; Idate, A.S.; Colby, D.A.; White, K. Preparation of Azulene-Derived Fulvenedialdehydes and Their Application to the Synthesis of Stable adj-Dicarbaporphyrinoids. J. Org. Chem. 2012, 77, 2368-2381. [CrossRef]

89. Colby, D.A.; Lash, T.D. Adaptation of the Rothemund Reaction for Carbaporphyrin Synthesis: Preparation of meso-Tetraphenylazuliporphyrin and Related Benzocarbaporphyrins. Chem. Eur. J. 2002, 8, 5397-5402. [CrossRef]

90. Okujima, T.; Kikkawa, T.; Nakano, H.; Kubota, H.; Fukugami, N.; Ono, N.; Yamada, H.; Uno, H. Retro-Diels-Alder Approach to the Synthesis of $\pi$-Expanded Azuliporphyrins and Their Porphyrinoid Aromaticity. Chem. Eur. J. 2012, 18, 12854-12863. [CrossRef] 
91. Noboa, M.A.; AbuSalim, D.I.; Lash, T.D. Azulichlorins and Benzocarbachlorins Derived Therefrom. J. Org. Chem. 2019, 84, 11649-11664. [CrossRef]

92. Richter, D.T.; Lash, T.D. Synthesis of Sapphyrins, Heterosapphyrins, and Carbasapphyrins by a " $4+1$ " Approach. J. Org. Chem. 2004, 69, 8842-8850. [CrossRef]

93. Berlicka, A.; Sprutta, N.; Latos-Grazynski, L. Dithiaethyneazuliporphyrin-A contracted heterocarbaporphyrin. Chem. Commun. 2006, 3346-3348. [CrossRef]

94. Zhang, Z.; Ferrence, G.M.; Lash, T.D. MacDonald-Type Reactions Using Bis-acrylaldehydes: Synthesis of an Expanded Sapphyrin and Vinylogous Hexaphyrins. Org. Lett. 2009, 11, 1249-1252. [CrossRef] [PubMed]

95. Larsen, S.; McCormick-McPherson, L.J.; Teat, S.J.; Ghosh, A. Azulicorrole. ACS Omega 2019, 4, $6737-6745$. [CrossRef]

96. Fujino, K.; Hirata, Y.; Kawabe, Y.; Morimoto, T.; Srinivasan, A.; Toganoh, M.; Miseki, Y.; Kudo, A.; Furuta, H. Confusion and Neo-Confusion: Corrole Isomers with an NNNC Core. Angew. Chem. Int. Ed. 2011, 50, 6855-6859. [CrossRef] [PubMed]

97. Okujima, T.; Inaba, H.; Mori, S.; Takase, M.; Uno, H. Synthesis of azulitriphyrin(2.1.1). J. Porphyrins Phthalocyanines 2020, 24, 394-400. [CrossRef]

98. Lash, T.D.; Stateman, L.M.; AbuSalim, D.I. Synthesis of Azulitriphyrins(1.2.1) and Related Benzocarbatriphyrins. J. Org. Chem. 2019, 84, 14733-14744. [CrossRef] [PubMed]

99. Kuzuhara, D.; Yamada, H.; Xue, Z.-L.; Okujima, T.; Mori, S.; Shen, Z.; Uno, H. New synthesis of meso-free-[14]triphyrin(2.1.1) by McMurry coupling and its derivatization to $\mathrm{Mn}(\mathrm{I})$ and $\operatorname{Re}(\mathrm{I})$ complexes. Chem. Commun. 2011, 47, 722-724. [CrossRef] [PubMed]

100. Sasaki, Y.; Takase, M.; Okujima, T.; Mori, S.; Uno, H. Synthesis and Redox Properties of Pyrrole- and Azulene-Fused Azacoronene. Org. Lett. 2019, 21, 1900-1903. [CrossRef]

101. Takase, M.; Enkelmann, V.; Sebastiani, D.; Baumgarten, M.; Muellen, K. Annularly Fused Hexapyrrolohexaazacoronenes: An Extended $\pi$ System with Multiple Interior Nitrogen Atoms Displays Stable Oxidation States. Angew. Chem. Int. Ed. 2007, 46, 5524-5527. [CrossRef]

102. Shoji, T.; Sugiyama, S.; Kobayashi, Y.; Yamazaki, A.; Ariga, Y.; Katoh, R.; Wakui, H.; Yasunami, M.; Ito, S. Direct synthesis of 2-arylazulenes by [8+2] cycloaddition of $2 H$-cyclohepta[b]furan-2-ones with silyl enol ethers. Chem. Commun. 2020, 56, 1485-1488. [CrossRef] 